\title{
BMJ Open Characterising the outcomes, impacts and implementation challenges of advanced clinical practice roles in the UK: a scoping review
}

Catrin Evans (D , ${ }^{1}$ Brenda Poku, ${ }^{2}$ Ruth Pearce ${ }^{3}$ Jeanette Eldridge, ${ }^{4}$ Paul Hendrick, ${ }^{1}$ Roger Knaggs, ${ }^{5}$ Holly Blake, ${ }^{1}$ Gowsika Yogeswaran, ${ }^{4}$ John McLuskey, ${ }^{1}$ Philippa Tomczak, ${ }^{2}$ Ruaridh Thow, ${ }^{6}$ Peter Harris, ${ }^{7}$ Joy Conway (D),${ }^{8}$ Richard Collier ${ }^{9}$

To cite: Evans C, Poku B, Pearce R, et al. Characterising the outcomes, impacts and implementation challenges of advanced clinical practice roles in the UK: a scoping review. BMJ Open 2021;11:e048171. doi:10.1136/ bmjopen-2020-048171

- Prepublication history and additional supplemental material for this paper are available online. To view these files, please visit the journal online (http://dx.doi.org/10.1136/ bmjopen-2020-048171).

Received 19 December 2020 Accepted 23 June 2021

Check for updates

(C) Author(s) (or their employer(s)) 2021. Re-use permitted under CC BY-NC. No commercial re-use. See rights and permissions. Published by BMJ.

For numbered affiliations see end of article.

Correspondence to

Dr Catrin Evans;

catrin.evans@nottingham.ac.uk

\section{ABSTRACT}

Objectives In response to demographic and health system pressures, the development of non-medical advanced clinical practice (ACP) roles is a key component of National Health Service workforce transformation policy in the UK. This review was undertaken to establish a baseline of evidence on ACP roles and their outcomes, impacts and implementation challenges across the UK. Design A scoping review was undertaken following JBI methodological guidance.

Methods 13 online databases (Medline, CINAHL, ASSIA, Embase, HMIC, AMED, Amber, OT seeker, PsycINFO, PEDro, SportDiscus, 0steopathic Research and PenNutrition) and grey literature sources were searched from 2005 to 2020 . Data extraction, charting and summary was guided by the PEPPA-Plus framework. The review was undertaken by a multi-professional team that included an expert lay representative.

Results 191 papers met the inclusion criteria (any type of UK evidence, any sector/setting and any profession meeting the Health Education England definition of ACP). Most papers were small-scale descriptive studies, service evaluations or audits. The papers reported mainly on clinical aspects of the ACP role. Most papers related to nursing, pharmacy, physiotherapy and radiography roles and these were referred to by a plethora of different titles. ACP roles were reported to be achieving beneficial impacts across a range of clinical and health system outcomes. They were highly acceptable to patients and staff. No significant adverse events were reported. There was a lack of cost-effectiveness evidence. Implementation challenges included a lack of role clarity and an ambivalent role identity, lack of mentorship, lack of continuing professional development and an unclear career pathway.

Conclusion This review suggests a need for educational and role standardisation and a supported career pathway for advanced clinical practitioners (ACPs) in the UK. Future research should: (i) adopt more robust study designs, (ii) investigate the full scope of the ACP role and (iii) include a wider range of professions and sectors.

\section{BACKGROUND}

Like countries all over the world, the National Health Service (NHS) in England and across
Strengths and limitations of this study

- This is the first attempt to comprehensively map the evidence on advanced clinical practice roles across all sectors, professions and settings in the UK, highlighting clear implications for national health workforce policy development. The review covers ACP roles in all health professions, hence, has a broad relevance and applicability.

- The use of an internationally recognised framework (PEPPA-Plus) to map the outcomes, impacts and implementation challenges of advanced practice roles boosts the international relevance of the findings.

- This was an extremely wide ranging and comprehensive review that was underpinned by a careful, comprehensive and systematic search strategy.

- Ongoing ambiguity and variability of advanced clinical practice roles and titles within the UK means that some relevant studies may nonetheless have been missed or misclassified.

the UK is facing unprecedented pressures associated with ageing populations, rising demand, rising costs, increasing health inequalities, workforce shortages and, more recently, the coronavirus pandemic. ${ }^{1-3}$ NHS policies such as the NHS Long Term Plan (2019), ${ }^{45}$ the NHS People Plan $(2020)^{67}$ and the General Practice Forward View $(2016)^{8}$ set out a vision for significant change in future service delivery with a concomitant need to develop models of care that cross traditional sectors and professional boundaries. $^{4-13}$ In order to support service development, there is considerable attention being given to the potential for non-medical advanced clinical practice (ACP) roles to contribute to the transformation agenda. ${ }^{5-714-19}$

These developments mirror policy initiatives and debates on 'task shifting' and optimal workforce skill mix in many other countries, ${ }^{20-26}$ and are supported by international systematic review evidence that 
advanced practice roles are safe, effective, have high levels of patient satisfaction and produce a range of benefits for service accessibility and efficiency. ${ }^{27-55}$ In many countries, ACP roles are separately regulated and are underpinned by standardised training programmes. ${ }^{20}{ }^{56-58} \mathrm{In}$ contrast, in the UK, advanced roles have evolved more organically in response to local need, local health service commissioning decisions and profession-specific imperatives rather than as part of an overarching national health workforce plan. ${ }^{58} 59$ As a result, there has been a proliferation of roles with different titles, different job descriptions, different scope of practice and different educational requirements (particular confusion relates to roles with titles such as 'extended' or 'specialist' practitioner vis a vis 'advanced' practice roles) ${ }^{58-60}$ Moreover, the definition and understanding of advanced roles have differed both within as well as between professions. ${ }^{61}$ This variability and lack of consistency gives rise to concerns for patient safety and impedes workforce planning at scale. ${ }^{62-64}$

In England, the NHS workforce transformation agenda is being supported by a national non-departmental public body, 'Health Education England' (HEE). HEE is spearheading a range of developments to bring greater national consistency around ACP, and, in 2017, it published a 'Multiprofessional Framework for Advanced Clinical Practice' for England that sought to provide a clear definition of ACP. ${ }^{65}$ The HEE framework states that:

Advanced clinical practice is delivered by experienced, registered health and care practitioners. It is a level of practice characterised by a high degree of autonomy and complex decision-making. This is underpinned by a master's level award or equivalent that encompasses the four pillars of clinical practice, leadership and management, education and research, with demonstration of core capabilities and area specific clinical competence. Advanced clinical practice embodies the ability to manage clinical care in partnership with individuals, families and carers. It includes the analysis and synthesis of complex problems across a range of settings, enabling innovative solutions to enhance people's experience and improve outcomes.

In this definition, ACP is established as a level of practice applicable across professions, rather than a specific role. A key distinguishing feature of ACP is the level of autonomy exercised by a practitioner as well as an ability to operate at an autonomous advanced level across four domains, including, but not limited to, clinical practice. These are referred to as the four 'pillars' of ACP (education, leadership, research and clinical practice), and the framework describes a set of generic core capabilities that should be achieved within each pillar. ${ }^{65}$

The HEE ACP framework applies specifically to England but has been developed in collaboration with relevant stakeholders across the UK and has been informed by existing advanced practice frameworks from the other three countries. ${ }^{15} 1718$ The framework aims to support NHS providers to enable delivery of sustainable health and care services. It also recognises that introducing, developing and supporting ACP within an organisation requires good governance in order to embed ACP in the workplace. ${ }^{65}$ The urgency of this agenda has been thrown into sharp relief during the coronavirus pandemic where advanced clinical practitioners (ACPs) have been required to work in new ways and with even greater autonomy. ${ }^{3}$

In a related development, HEE is leading the establishment of a 'Centre for Advancing Practice'. The Centre's role is to strengthen governance arrangements for advanced level practice by recognising practitioners working at an advanced level through two routes: (i) accreditation of university education programmes and (ii) an HEE recognition route that an individual can follow.

In order to inform this ambitious programme of work, HEE commissioned a team at the University of Nottingham to undertake a review that would identify and summarise the existing available evidence on ACP across the four countries of the UK. This recognises that while advanced roles in certain professions have a strong evidence base internationally, there is a need to establish a baseline of evidence for ACP roles specifically within the UK context. Nonetheless, given the international imperative around advanced practice role development, the review outcomes will be of interest to other countries currently considering the development of similar roles.

The review aim was to characterise the current evidence base underpinning multi-professional advanced level practice from a workforce, clinical, patient and service perspective in the UK. Specific objectives were:

- To identify what evidence exists about implementation, impacts and outcomes of advanced clinical practice in the UK across (i) different professions, (ii) different sectors and (iii) different specialities.

- To identify the challenges reported to affect advanced level practice implementation by sector, specialty and profession in the UK.

- To identify and describe the different types of outcomes and impacts of advanced level practice roles that have been reported, and to summarise existing knowledge on these, by sector, specialty and profession in the UK.

- To identify key gaps in the existing evidence base and the most urgent questions for future research.

- To consider how advanced level practice is being defined, conceptualised and applied across professions and the public, private and voluntary sectors of service provision.

\section{METHODS AND METHODOLOGY}

The aim of this review was to identify and map the existing evidence (rather than to synthesise it in relation to a specific question), hence, it adopted a scoping review methodology, following JBI guidance. ${ }^{67-69}$ The review 
was registered with Open Science Framework. ${ }^{70}$ A highly detailed protocol was published in $2020^{71}$ (see online supplemental file 1). For this reason, the description of methods below is relatively brief-the protocol provides a full justification and explanation of all methodological steps and decisions. The review is reported in line with the Preferred Reporting Items for Systematic Reviews and Meta-Analyses (PRISMA) reporting guidance (extension for scoping reviews). ${ }^{72}$

\section{Searching}

A highly comprehensive and complex search strategy was implemented between November 2019 and February 2020 across 13 online databases and grey literature sources (see online supplemental file 2 for a list of all information sources and online supplemental file 3 for a full search strategy as applied within Medline). Reference lists of included studies and systematic reviews were also scrutinised (but systematic reviews were not included as papers in the review). The review included evidence that met the following criteria: (i) primary research, service evaluations or audits of any study design, including grey literature; (ii) reported on ACP roles or services fulfilling the HEE definition of ACP; (iii) reported on an established role or service (ie, did not include trainees); (iv) any profession; (v) any sector and any setting and (vi) must be in the UK (England, Scotland, Northern Ireland, Wales). A UK-focused search filter (based on previously published search filters ${ }^{73} 74$ was incorporated into the overall search strategy to limit the search results to UK-focused studies, including relevant international studies that involved the UK. The latter were considered for inclusion, provided UK data were reported separately. The date range of the search was 2005-onwards. The rationale for the date limit of 2005 is due to the timing of key policy developments around advanced clinical practice in the UK. Prior to this date, most advanced clinical practice roles and research were limited to nursing and referred to a wide range of highly inconsistent titles, educational preparation, role definitions and scope of practice. ${ }^{60}$

\section{Screening and study selection}

Study screening and selection was undertaken by two reviewers $(\mathrm{CE}, \mathrm{BP})$ working independently. The greatest challenge in the search and study selection related to the highly varied terminology used to describe ACP roles. This resulted in a preanticipated large number of records being retrieved, both for the initial screening process as well as for review of the full text. Each record was scrutinised for descriptions and evidence that the role met the HEE criteria. In cases where the role title included the term 'advanced' but details within the paper showed that it did not meet the HEE definition, it was excluded. Likewise, in cases where the role title did not include the word advanced but described a role that met the HEE criteria, it was included. Where the two independent reviewers were unsure or could not agree, the paper was discussed with another team member (sometimes with several team members) and advice was sought from experts representing different professions. Excluded papers were listed in a table with reasons for exclusion noted (see online supplemental file 4 ).

\section{Data extraction, charting and summary}

Data charting and summary was undertaken using a framework approach, ${ }^{75}$ guided by the PEPPA-Plus framework-an internationally recognised and widely used framework for evaluating the structure, outcomes and implementation of ACP roles. ${ }^{76-78}$ Data extraction and charting was undertaken by three team members (CE, BP, GY). Following piloting of the framework template, GY undertook extraction and charting for the secondary care sector papers and BP did this for the papers in all the other sectors. CE independently extracted data from $20 \%$ of all papers as a measure to ensure quality control and consistency. The three team members met regularly together to discuss any queries and challenges and resolved these through consensus or by discussion with members of the wider team.

Data extraction/summary involved three steps (see online supplemental file 5 for the study characteristics and structure data extraction template and online supplemental file 6 for the outcomes and implementation data extraction template):

1. Charting key study characteristics relating to methodology, study aims and 'structural' features of ACP roles (eg, title, profession, sector, setting, stage of role implementation). As per scoping review guidance, formal quality appraisal was not undertaken.

2. Extracting and summarising data related to ACP outcomes according to five key outcome domains, each with predefined subdomains: (i) patient and family (eg, clinical/functional health status, health-related behaviours, healthcare experiences, perceptions/ satisfaction with care); (ii) quality of care (eg, patient safety, processes of care and access to care); (iii) healthcare provider, team and stakeholder (eg, healthcare team performance, knowledge/skills, acceptance and satisfaction with the ACP role, ACP role support); (iv) organisation (eg, recruitment and retention) and (v) healthcare use and costs (eg, length of stay, readmission rates, waiting times, cost avoidance, cost savings).

3. Using thematic analysis ${ }^{79}$ to code study findings and identify key themes affecting ACP implementation (using NVIVO V.12 Pro software ${ }^{80}$ ).

Data from steps 1 and 2 were analysed using descriptive summaries presented numerically (eg, percentages in tables or figures) or narratively. Data from step 3 were analysed thematically. ${ }^{79}$ As per the review objectives, the narrative summaries sought to characterise the evidence base as a whole while drawing attention to any sector, specialty and professional-specific commonalities and differences. 


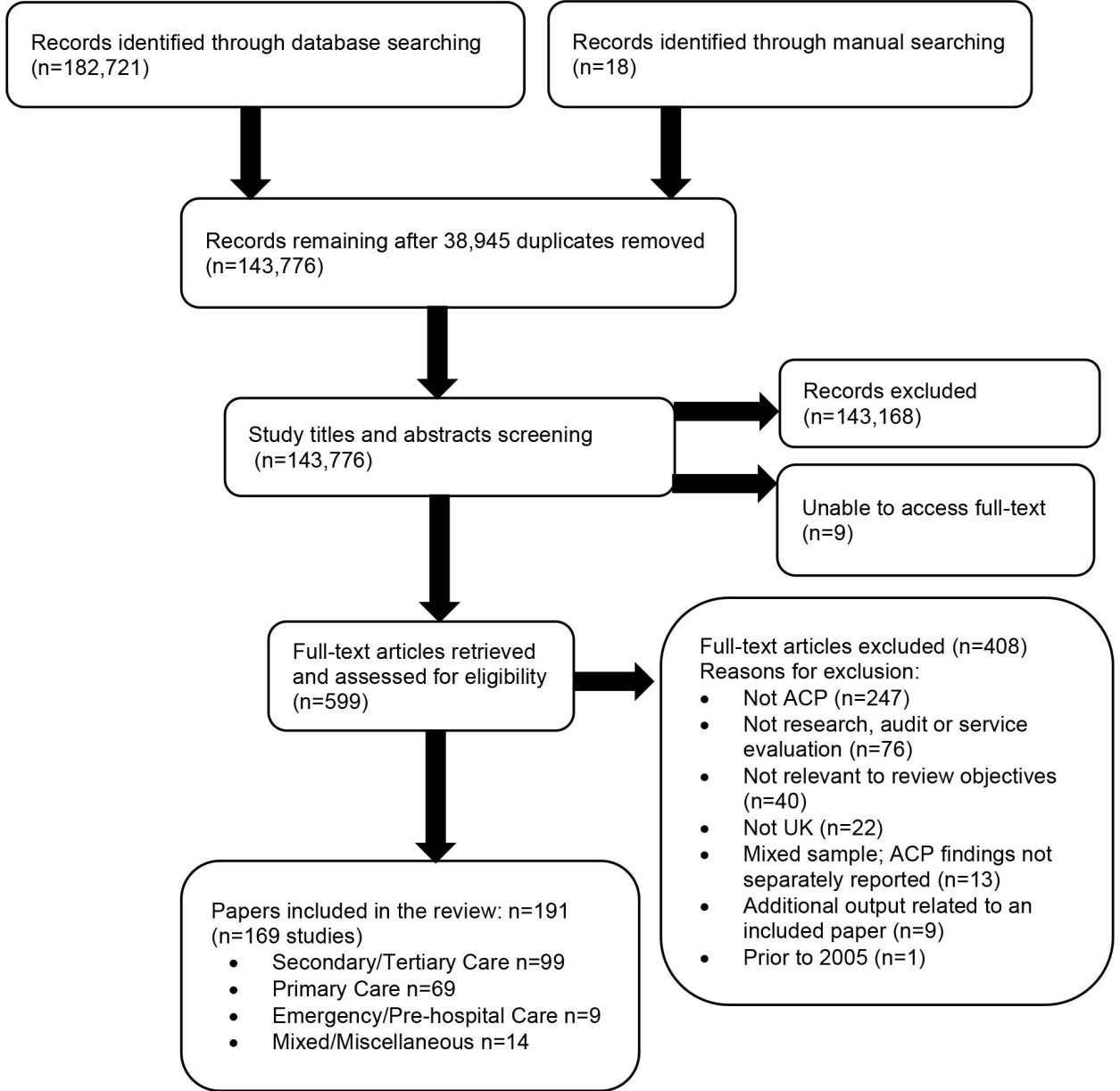

Figure 1 Preferred Reporting Items for Systematic Reviews and Meta-Analyses flow diagram.

\section{Patient and public involvement}

The review was conducted by a multi-professional, multidisciplinary team including an experienced librarian. A lay representative within HEE $(\mathrm{PH})$ was a key part of the team and was involved at every stage. He was particularly instrumental in ensuring that patient and family perspectives were reflected in the review objectives and highlighted in the discussion points and recommendations.

\section{RESULTS}

This review had a wide and highly comprehensive scope and included a large number of papers (see later). Hence, in order to maintain readability, the results are necessarily presented in a highly summarised form. Online supplemental files have been extensively used to provide the reader with more detail, and to maintain the rigour and transparency required to meet robust scientific standards. ${ }^{69} 72$

\section{Literature search}

Records were imported into EndNote, a reference management programme. After deduplication of records, 143776 were screened; 599 records were reviewed as fulltext papers and 191 papers (representing 169 distinct studies) were included in the final review.
See the PRISMA ${ }^{81}$ flow diagram in figure 1 for a summary of the search process.

\section{Study characteristics and structural features of the ACP role}

The 191 papers were categorised into four sectors: (i) primary care, (ii) secondary/tertiary care, (iii) emergency/prehospital care and (iv) a mixed/miscellaneous group. The latter relates to papers reporting evidence across multiple sectors or from a small number of other settings (see online supplemental file 7 for full tabular summaries of key study characteristics organised per sector).

\section{Study design}

In terms of study design, overall there was a preponderance of relatively small-scale (eg, single-site, single-Trust, single-service, single-practitioner) studies, reflected by the fact that $61 \%$ of the papers $(n=116)$ were reporting service evaluations or audits. The majority of papers used quantitative designs $(n=112), 27 \%(n=52)$ used a qualitative approach and $14 \%(n=27)$ were mixed-method. Most quantitative papers used descriptive or observational designs. Only three papers reported Randomised Control Trials (RCTs) ${ }^{82-84}$ Two additional papers reported on a pilot study ${ }^{85}$ linked with one of these RCTs and an associated economic evaluation. ${ }^{86}$ Three papers used 
Table 1 Included papers per sector

\begin{tabular}{llll} 
Sector & Papers (n) & Studies (n) & References \\
\hline Secondary/tertiary care & 99 & 92 & 82 89-108 127 128 130-133 135-139 147-157 202-257 \\
Primary care & 69 & 55 & $84-88$ 109-119 129 140-146 158-175 258-284 \\
Emergency and prehospital care & 9 & 9 & 83 134 285-291 \\
'Other' sectors/settings, including: & 14 & 13 & 120-126 176 177 292-296 \\
- Multiple/mixed sectors & & & \\
- Mental health trusts & & & \\
- Community learning disability team & & & \\
- Alcohol and drug services & & & \\
- ADHD clinic & &
\end{tabular}

ADHD, Attention Deficit Hyperactivity Disorder.

quasi-experimental designs. ${ }^{87-89}$ See online supplemental file 8 for more details on study design and scope.

Sector, profession, setting and date

The majority of papers related to primary and secondary/ tertiary care sectors ( $n=69$ and $n=99$, respectively). A small number focused on emergency/prehospital care $(n=9)$ and a small number were categorised as 'miscellaneous', representing mixed sectors $(n=14)$. Table 1 includes the paper references per sector.

Half the papers $(n=95)$ were published within the last 5 years indicating that most evidence around ACP is relatively recent. The majority of papers $(n=148)$ were from settings in England.
The papers mainly represented four professions: nursing $(n=77)$, pharmacy $(n=34)$, radiography $(n=34)$ and physiotherapy $(n=32)$. A minority of papers related to other professions or had mixed samples (midwifery, audiology, healthcare scientist, paramedic, occupational therapy, perioperative specialist practitioner). There were no papers related to social care. Table 2 gives the references of the papers categorised per profession.

\section{Terminology}

A key finding was that across the papers and professions, ACP was referred to by a multitude of different titles, some of which denoted the profession but not the advanced level (eg, nurse practitioner), some of which denoted the

Table 2 Papers according to professions

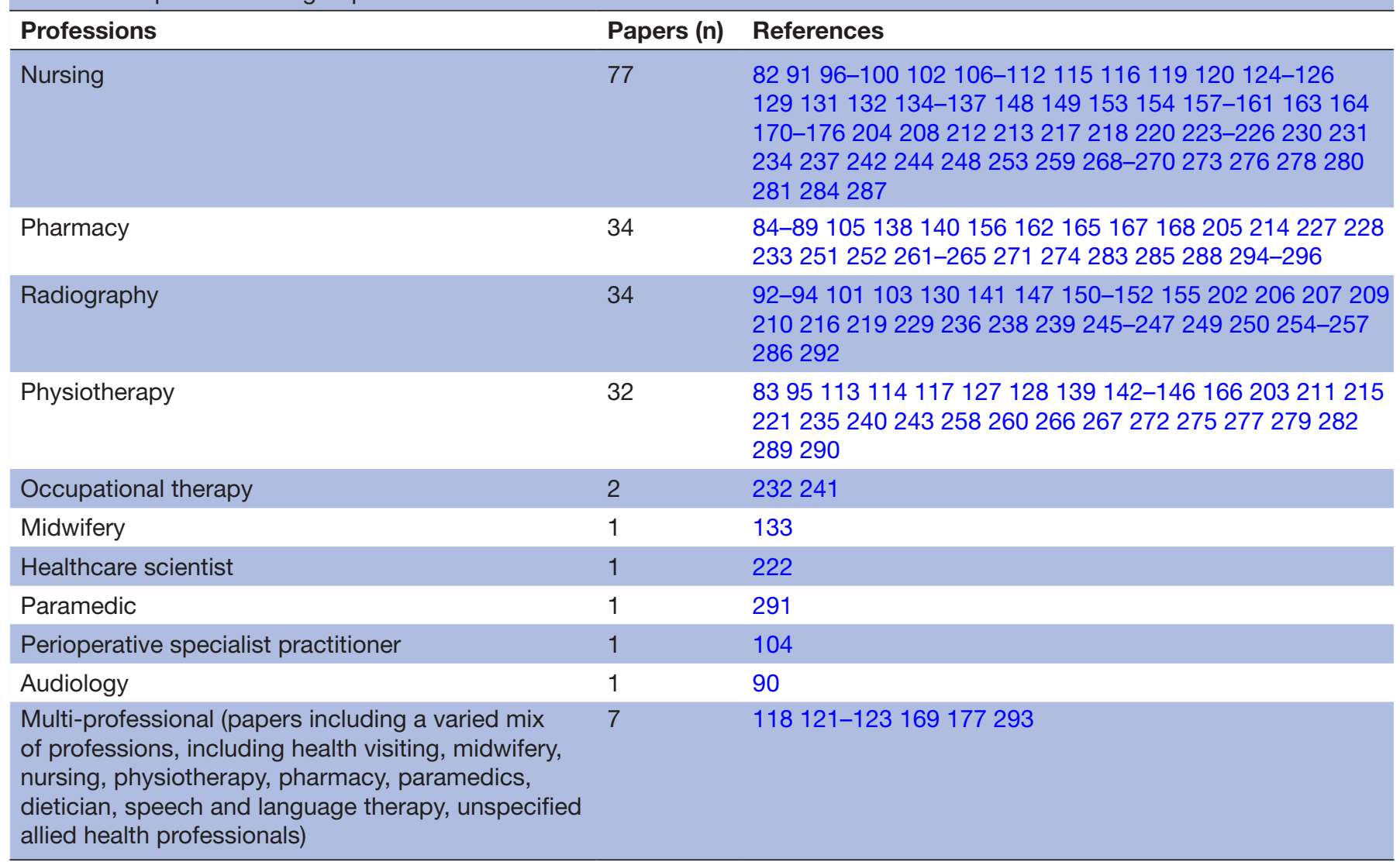




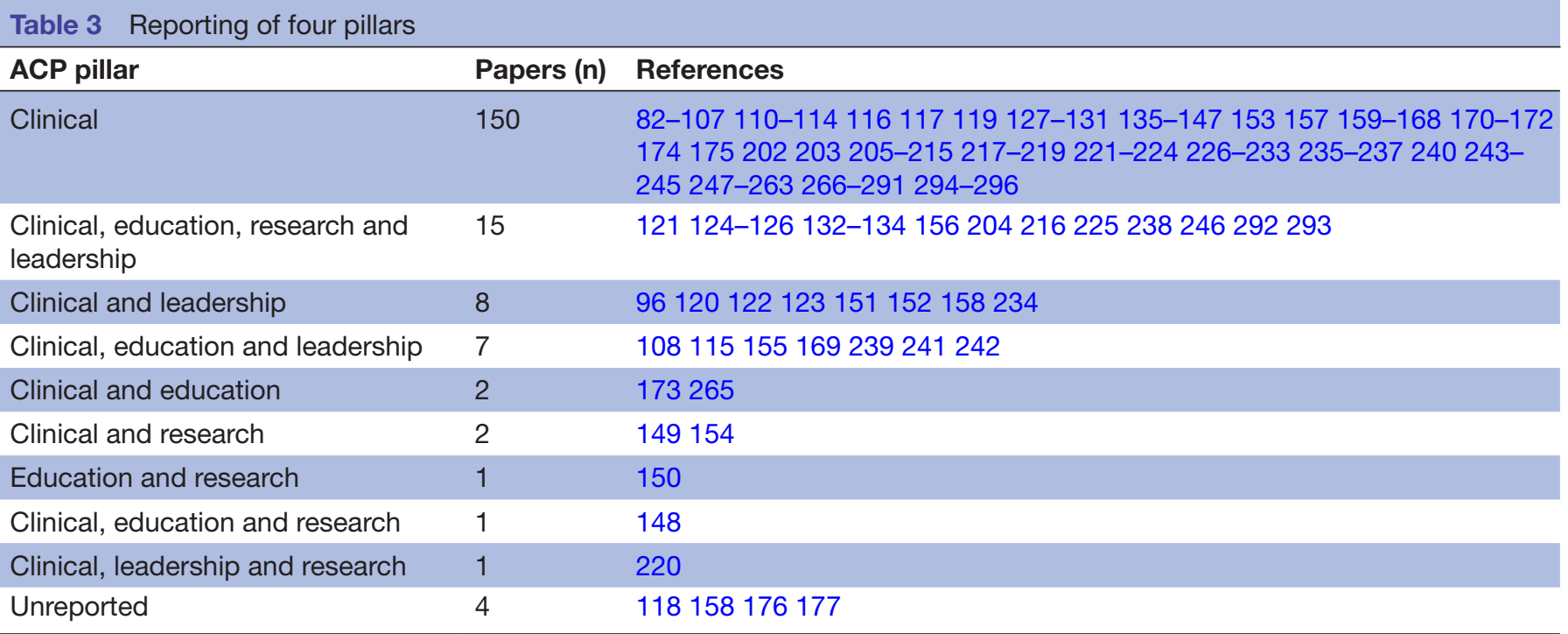

ACP, Advanced Clinical Practice; ACPs, Advanced Clinical Practioners.

level but not the profession (eg, advanced practitioner), and some of which denoted neither the level nor the profession (eg, extended scope practitioner). For the four major professions represented (nursing, pharmacy, radiography, physiotherapy), the number of different role titles reported in the papers was, respectively: 15, 13, 13 and 17 (see online supplemental file 9 for a table listing all the ACP role titles found in the papers per profession).

\section{Reporting of ACP 'pillars'}

The majority of the papers $(n=150)$ reported exclusively on the clinical pillar of the ACP role; $16 \%$ of papers included some element of advanced clinical practitioners' (ACPs) leadership role, $13 \%$ included education and only $10 \%$ included research. More detail is provided in table 3 .

\section{ACP role implementation stage}

One hundred and fifty papers provided details on the stage of ACP role implementation. Of these, only 39 papers reported on roles that had been implemented for over 2 years. ${ }^{90-126}$ This suggests that many studies and evaluations of the ACP role are taking place when the role is still in the relatively early stages or are not explicitly including role maturity within their analytical framework.

\section{Evidence related to ACP outcomes}

The evidence related to ACP outcomes was organised into five overarching domains, each with a number of subdomains. These correspond to the domains of the PEPPAPlus Framework. ${ }^{78}$ See figure 2 for the number of papers per outcome domain, and see online supplemental file 10 for a detailed table of outcome domains and subdomains linked to the papers reporting on these according to sector. In terms of over-arching outcome domains, a large number of papers reported on 'healthcare provider and stakeholder' outcomes ( $\mathrm{n}=104$ papers) and 'healthcare use and cost' outcomes ( $\mathrm{n}=104$ papers). Less than half the papers $(n=73)$ reported on 'patient and familyrelated' clinical outcomes, just over a quarter of the papers reported on 'quality of care' related outcomes $(n=51)$ and only five papers reported on outcomes related to 'organisation, professional and workforce' issues.

The most commonly reported outcome subdomains were 'appropriateness of care' $(n=91)$ and 'patient perceptions/experiences of ACP roles' $(n=66)$. The

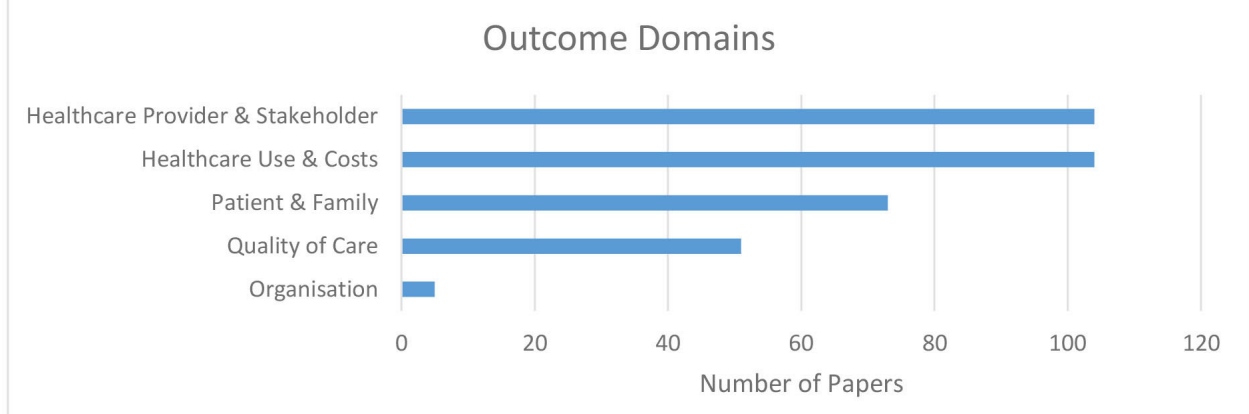

Figure 2 Number of papers per outcome domain. 


\section{Outcome Sub-Domains}

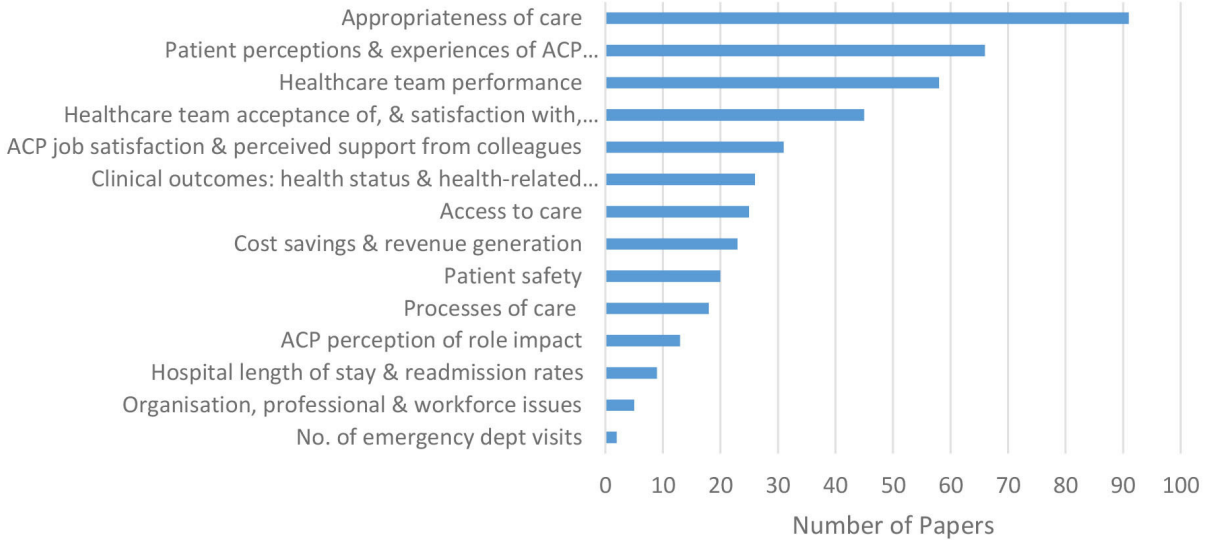

Figure 3 Number of papers per outcome subdomain.

number of papers reporting other subdomains ranged from 58 (healthcare team performance) to 2 (number of emergency department visits). Of note is that only $14 \%$ of papers $(n=26)$ reported on clinical outcomes relating to health status and behaviour and only $10 \%$ of studies $(n=20)$ reported on patient safety-related outcomes. See figure 3 for the number of papers per outcome subdomain.

\section{Outcome domain 1: patient and family outcomes}

ACP-led care was reported to be achieving positive clinical, functional and health behaviour-related outcomes across a wide range of conditions and settings. ACP-led care was reported to be highly acceptable to patients and their families with most studies reporting high levels of satisfaction. Of note is that only five of the papers reporting on patients' health status were based on experimental $(\mathrm{RCT})^{82-84}$ or quasi-experimental study designs. ${ }^{87} 88$ A very small number of studies reported resistance from patients towards ACP-led consultations but this was primarily linked to a lack of awareness of the ACP role and skill set. $^{115} 127-129$

\section{Outcome domain 2: quality of care outcomes}

ACP roles and services were reported to lead to improved access to care and improved systems and processes of care delivery. Where reported, the papers suggest that most ACP roles and services achieved positive impacts on patient safety. However, six studies conducted in the last 3 years, reported statistically non-significant adverse events or complications associated with ACP roles and services (compared with set clinical targets or prevalence of adverse events prior to the introduction of ACP roles and services). ${ }^{96-99} 130131$

Outcome domain 3: healthcare provider and stakeholder outcomes ACPs were reported to have a positive impact on healthcare team performance in terms of creating capacity within the team for more flexible and efficient allocation of tasks and responsibilities. The impact on medical doctors' workloads was less clear cut. Some papers reported a beneficial impact, but others suggested that medical workloads may have become more complex (and sometimes more stressful), with some medical practitioners having to take on additional supervision and training responsibilities for the ACPs. Overall, the evidence suggested that ACP roles are well accepted and valued by the wider healthcare team and are perceived to be making important contributions to, and improvements in, patient care and service delivery. Key areas of concern (especially in primary care) related to the variability in ACPs' backgrounds, education and competence leading to uncertainty around defining an appropriate scope of practice. In many settings, highly specialist and more experienced ACPs were particularly valued. In general, ACPs were reported to find their work enjoyable, satisfying and interesting. Role tensions and lack of support were associated with settings where the ACP scope of practice was not clear or where the role was not well planned. A small number of papers $(n=5),{ }^{123} 125$ 132-134 particularly relating to non-medical consultant level roles, reported challenges with excessive workloads. ACPs perceived their roles as having a wide range of positive impacts for patient care, for other team members and for improvement of service delivery processes.

\section{Outcome domain 4: healthcare use and costs}

The evidence on appropriateness of care suggested that ACP-led care meets service/role objectives and leads to desired service outcomes. ACP-led care was reported to be associated with improvements in key areas such as hospital readmission rates and length of hospital stay. However, direct evidence on cost savings and revenue generation associated with ACP roles and services was limited and highly descriptive. Twenty-two of the papers reported actual or inferred cost savings and revenue generation. These were associated with: (i) reduced 
running costs of ACP-led services compared with doctor-led services, ${ }^{92} 102$ 135-137 (ii) clinical interventions/ procedures related to ACP services, ${ }^{108}{ }^{138-141}$ (iii) release of medical practitioner capacity ${ }^{90142}$ and (iv) reduction in healthcare use. ${ }^{139} 143-146$ Only one (pharmacy-related) study included a robust economic evaluation. ${ }^{86}$ Of note is that none of the papers took into account costs associated with role introduction or implementation (eg, education, training, supervision, mentorship). Likewise, single sites and small sample sizes limit the interpretations of costrelated data. None of the studies took into account the effects of ACPs' level of experience and 'service maturation' (length of time in role) on cost. In addition, none of the studies explored economic impacts of ACP roles/ services for service users.

\section{Outcome domain 5: organisational, professional and workforce issues}

There was limited evidence related to the impact of ACPs on recruitment and retention of staff practising as ACPs or on their associated teams. The evidence suggested that ACP roles helped to create positive working environments. In some cases, however, particularly, for nonmedical consultant level roles, more work may be needed to optimise workloads and to provide professional support structures.

\section{Evidence related to ACP implementation}

Just over one-quarter $(n=51)$ of the 191 papers highlighted factors that hindered or facilitated the development, implementation and sustainability of ACP roles and services. ${ }^{8691102104111-113115118120-122125126132-134137142147-178}$ The majority of these papers were nursing-focused $(n=24)^{91} 102$ 111 112 115120-122 125126132134137148149153154157-161 163164170-177 and based in primary care $(\mathrm{n}=26) .^{86111-113115118142158-175178}$ The evidence was interpreted into eight themes: (i) autonomy, (ii) rationale for ACP roles and services, (iii) role definition, (iv) role awareness, (v) funding, (vi) role evaluation and cross-organisational engagement, (vii) education, support and training and (viii) career progression and pathway. See online supplemental file 11 for a detailed table elaborating the meaning of each theme and linking each of the themes to the papers and sectors that related to them. Figure 4 depicts the different theme areas according to the frequency of reporting. The findings from the themes were then inferred in relation to factors that appeared to hinder and facilitate ACP role implementation.

\section{Factors that hindered ACP role implementation}

The main challenges reported for ACP role implementation were related to a perceived lack of integration of the ACP role into wider workforce plans, and a lack of clarity among organisations and stakeholders regarding role preparation, role definition and scope of practice. This in turn was linked to wide variations in educational backgrounds and competencies among current role holders (this appeared to be a particular problem for nursing and for the primary care sector). Lack of role clarity created tensions related to understanding role boundaries, developing a professional identity and enacting role autonomy. The papers identified a felt need for greater supervision, mentorship, continuing professional development (CPD) and a clear career pathway. Where these were not in place, this was seen to be linked to lack of funding and strategic planning. All these challenges were perceived to be linked to future role retention and role sustainability.

\section{Factors that facilitated ACP role implementation}

Conversely, the papers linked successful ACP role implementation/sustainability to role preparation (eg, roles that were integrated into strategic workforce plans with adequate funding attached), role clarity, provision of ongoing CPD, mentorship and a clear career progression pathway. A sense of role clarity was linked to greater standardisation (of ACP education/training, of ACP scope of practice and of ACP titles), and greater awareness of ACP roles and scope of practice among relevant stakeholders. Likewise, the papers suggested that role performance was enhanced by consistent clinical governance processes, ongoing mentorship and continued professional development opportunities. Finally, the findings suggested that role sustainability would be enhanced by ongoing role evaluation and the development of a structured career pathway.

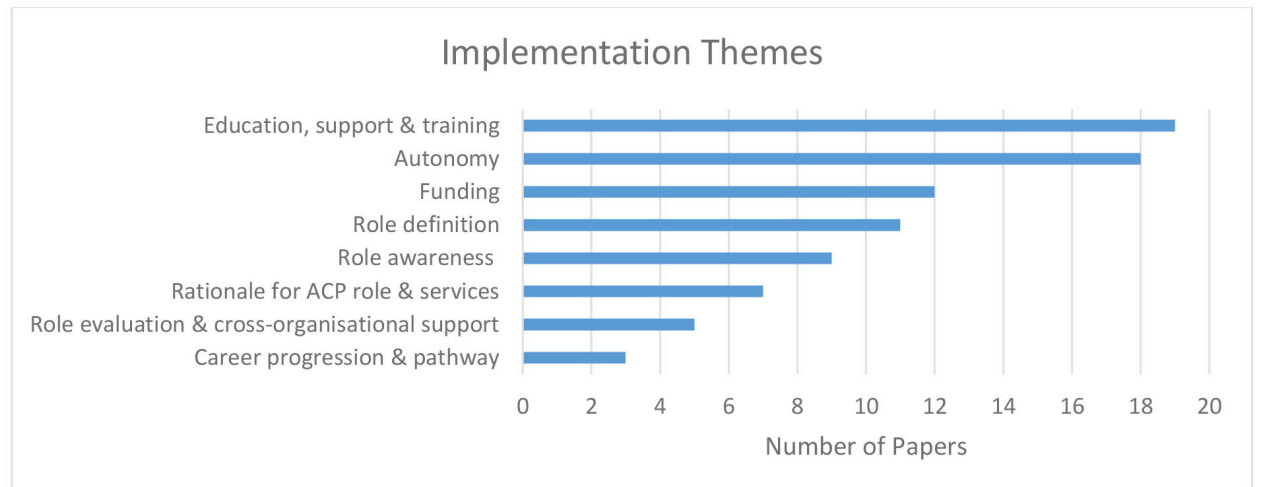

Figure 4 Frequency of implementation theme reporting. 


\section{DISCUSSION}

This scoping review included 191 papers. The discussion sets out key insights derived from the review and contextualises these in terms of existing evidence and policy directives. Recommendations for future policy development and research are made.

\section{Breadth of ACP role: adoption of ACP roles across sectors and professions}

The review showed that most ACP roles are being implemented in a wide range of settings and specialisms in primary, secondary/tertiary and prehospital care sectors within the NHS. There was minimal evidence from other settings or sectors, however. In particular, there was a dearth of evidence on ACP in the context of mental health or learning disability settings or social work/ social care settings. Contemporary developments in ACP suggest that these roles are being implemented much more widely than the evidence currently reflects. ${ }^{179}$ There is a need, therefore, for ongoing research to capture the impacts of ACP roles across a wider range of healthcare settings.

Similarly, the majority of evidence in the review (93\%) was focused on ACP roles within four professions (nursing, pharmacy, physiotherapy and radiography). This reflects the historical evolution of ACP in the NHS, but suggests that there is a need for more research to create an evidence base for ACP within the other professions. $^{38} 4151$ 180-182

\section{Outcomes and impacts of ACP roles}

Due to the highly heterogenous aims and contexts of the papers and the large number of small-scale descriptive studies, evaluations and audits, it is not possible to draw definitive conclusions regarding the outcomes and impacts of ACP roles and this was not the aim of this review. Scoping reviews provide a descriptive summary of evidence (rather than a synthesis aiming to definitively assess effectiveness of an intervention), moreover, they do not include a quality assessment of the studies. With these caveats in mind, the current evidence nonetheless suggests that ACPs are achieving beneficial outcomes for patient care across a range of clinical, functional and behavioural domains and are having a positive impact on service objectives around safety, efficiency and accessibility. This is consistent with systematic reviews of international evidence on advanced roles across settings, professions and sectors. ${ }^{33} 3540475053$ 183-186 The current evidence from the UK reports that patients/families are satisfied with ACP-associated care. In particular, they appreciate the person-centred approach and highly developed communication skills that ACPs, as experienced healthcare professionals, often bring to their role. These findings are in line with the international evidence on advanced level roles. ${ }^{3033} 35394043475053$ 183-186 A minority of studies reported that patients were sometimes uncertain about receiving ACP-led care. ${ }^{115}$ 127-129 This was primarily related to a lack of understanding of ACP skills and roles.
Hence, this finding suggests that it is important to raise awareness among the general public about ACP roles and about the safety and quality of care that they provide.

In line with the international picture, ${ }^{187}$ the review found limited evidence regarding the cost-effectiveness of ACP roles. Several studies suggest the potential for considerable cost savings and revenue generation, but a lack of robust full economic evaluation limits the ability to draw any further conclusions. Thus, future research should include a full economic evaluation.

Only $10 \%$ of the papers reported directly on patient safety-related outcomes. Although there were few papers, they reported ACP-led care to be safe and beneficial (eg, reducing errors in patients' medications through medication review and reconciliation, medicine optimisation, reducing prescriptions for patients, promoting a healthy lifestyle and preventative interventions and adhering to standards of care). Only six papers (relating to three clinical settings) reported statistically non-significant adverse outcomes. ${ }^{96-99} 130131$ The lack of reported adverse outcomes in the overall body of evidence is encouraging but also raises questions about potential publication bias. Given the small number of papers focusing on this area, additional investigations may be required to establish the safety of ACP-delivered care more confidently (such as an analysis of serious incident reports). Future research should include patient safety-related outcome measures.

\section{Implementation issues}

The review showed that there is a wide proliferation of titles for ACP roles being used across the UK. This variability was found across professions and sectors. Similar variability has been reported in studies related specifically to nursing in the UK. ${ }^{5960}$ For example, Leary $e t a l^{60}$ found 595 different job titles for specialist and advanced nurses (within a dataset of 17960 UK nurses collected over a 10-year period). The issue of ACP titles relates to other findings of the review suggesting that some of the barriers to smooth implementation of ACP roles were associated with a lack of understanding among relevant stakeholders of ACPs' role, scope of practice and capabilities. The variability in nomenclature was one of the issues contributing to this barrier.

A key action that could be taken to bring clarity and to aid mutual understanding of the ACP role would be to standardise job titles as appropriate to particular settings and professions. The multiplicity of titles currently in use appears to reflect an ongoing lack of clarity about whether ACP denotes a role, a level of practice or both ${ }^{61}$ (HEE's 2017 definition of ACP affirms that ACP reflects a level of practice, not a role) ${ }^{65}$ For example, within primary care, HEE has recently developed a core capability framework for advanced nursing practice in primary care, using the role title Advanced Clinical Practice (Nurse) — thus denoting the professional group. ${ }^{188}$ Other ACP roles, however, such as the Advanced Critical Care Practitioner (ACCP), are explicitly multi-professional and are represented as a new role as well as an advanced level role (eg, the Faculty of 
Intensive Care Medicine states that ACCP is a distinct role - they are 'clinical professionals' - that, with the right training, can be filled by individuals drawn from a range of different professional groups). ${ }^{189}$

The review also showed that the ambiguity caused by lack of standardisation in job titles was exacerbated by a lack of clarity around the definition and scope of practice of ACP roles, which were highly localised. This sometimes led to inter-professional tensions, role overlaps, misunderstandings of the role purpose and scope and a sense of dissonance around professional identity. ${ }^{61}$ Similar issues have been reported in other (international) reviews. ${ }^{190} 191$

Another key factor influencing ACP implementation was identified as the variability in the education and training pathways underpinning ACP roles. Although the situation is changing now ${ }^{188}$ (especially with the introduction of the Centre for Advancing Practice), historically ACPs have moved into their roles with widely varying educational backgrounds and via differing training routes. This has led to a situation where ACPs using similar titles may have quite different skill sets, knowledge, confidence and competencies. Similar challenges with variation in educational background have been reported in other international reviews, ${ }^{3464185191}$ suggesting an urgent need to standardise training pathways, to develop sector or specialty specific training and to communicate the nature of ACPs' capabilities across the health system. The review suggests that greater standardisation of education and training would enhance clarity regarding the ACP role among relevant stakeholders and facilitate the development of appropriate and consistent clinical governance processes.

The review highlighted a need for ongoing CPD, mentorship and support for ACPs, with several papers noting that this was not always available. This was partly attributed to lack of availability of relevant specialist training, lack

Table 4 Recommendations

\section{Research}

Research focus areas Ongoing research is needed to explore the impacts of ACP roles in a wider range of sectors/clinical settings (eg, mental health) and in a wider range of professional groups

ACP-related research studies should include a full economic evaluation in order to develop a better understanding of the cost-effectiveness of ACP roles within the health system

More research is needed to understand the impact of ACP roles/services on healthcare team performance and workload. There is also a need to evaluate long-term impact and evolution of roles

Methodological and conceptual issues

Research studies should adopt methodological approaches that are able to account for complexity (eg, case studies and mixed-method designs)

Research studies should investigate the ACP role/service across a system or network (or across multiple sites) to enable organisational contexts and variations to be fully explored and understood

Future research should take into account service maturation and the level of experience of ACPs

Future research should investigate impacts of the ACP role across all four pillars and seek to explore and explicate the ways in which the four pillars are integrated within advanced clinical practice

Future research should move beyond demonstrating ACP impacts within an implicit medical substitution paradigm (ie, ACP outcomes need to be compared appropriately and not just with medical professionals) and explicitly re-frame the enquiry within a service enhancement or service transformation paradigm

\section{Patient safety and engagement}

Additional investigations (eg, of serious untoward incident reports) may be needed to evaluate the safety record of ACP-led care

There is a need for greater awareness raising of ACP roles and the benefits of ACP care among the general public to enhance their knowledge, understanding and acceptance of these roles

Policy

Education and support There is a need for standardisation of education/training routes

Educational pathways need to cover specialist (as well as generalist) competencies

There is a need to support provision of, and access to continuing professional development for ACPs

There should be systems in place to provide ACPs with ongoing mentorship and clinical supervision

Governance/regulation There is a need for standardisation of role titles and nomenclature. This may require regulation

There should be greater consistency of clinical governance processes for ACP roles across settings/sectors. This may require regulation

ACP roles should be incorporated into strategic workforce plans at national/regional level to avoid localisation (especially in primary care) and to maximise their impact across the system

In order to maximise retention and job satisfaction, there is a need for clearer career pathways for ACPs Guidance for relevant stakeholders should be developed to assist with planning for ACP role implementation and evaluation (eg, toolkits) 
of funding or high workloads which prevented uptake of training opportunities. The review also highlighted that a lack of career pathway in some settings potentially impeded the ongoing development, motivation and job satisfaction of ACPs. Thus, the evidence suggests that as the ACP workforce grows, there is a clear need to provide structured ongoing CPD opportunities as part of a structured career pathway. ${ }^{61}$

\section{Methodological features of the evidence base}

The evidence in this review included quantitative studies, evaluations and audits (focusing on measures of competence, performance and clinical/service outcomes), qualitative studies (providing more detailed analysis of the nature of ACP implementation) and mixed-method studies (providing data on both aspects). Over half the papers were based on studies conducted within the last 5 years. Hence, the review shows that the evidence base on ACP roles across the UK is contemporary and substantial, providing data on all review objectives.

The majority of evidence was based on relatively smallscale and single-site investigations focused on a limited range of outcomes. The evidence is thus highly localised and the preponderance of descriptive observational studies introduces a high potential for bias and lack of certainty around the reported outcomes. As a result, it is hard to judge how transferable the key findings would be across the country or to other organisational contexts or practice settings. The findings on implementation challenges likewise highlighted wide variability in organisational contexts depending on the local setting, yet suggested that organisational context (eg, related to role clarity or support) played a critical part in successful role/service implementation. The way in which organisational context influences the magnitude, breadth and sustainability of outcomes is a key question for future ACP research. Given the complexity of ACP roles, it may be beneficial for future research to move beyond singlesite or single-design approaches and to more explicitly recognise ACP as a 'complex intervention' (ie, comprised multiple intersecting interventions being introduced into a dynamic multi-level system or network) $)^{192-194}$ and to adopt more robust study designs to take complexity and organisational context into account. In-depth, mixedmethod, multi-site case studies may help to address some of these challenges. ${ }^{192}$

\section{Conceptual issues: making the full potential of ACP roles visible}

This review provides an encouraging picture of the potential of ACPs to support the service transformations envisaged in the NHS Long Term Plan. Nonetheless, the review has highlighted some conceptual issues related to the current evidence that may be impeding the development of a full appreciation of the potential of ACP roles within the health system. There are three salient issues.

The first relates to an understanding of the multifaceted nature of the ACP role. The review demonstrated that most of the existing evidence ( $79 \%$ of papers) on ACP roles primarily and exclusively evaluated activities or outcomes related to the clinical pillar. It is unclear whether the limited amount of evidence related to the other ACP role pillars reflects the fact that ACPs are indeed focusing mainly on the clinical aspects of their role or whether the research has simply not yet focused on a more in-depth evaluation of ACPs' work related to the other role pillars. There is very little UK or international evidence related to the impact of ACP in terms of the research or education pillars. In relation to leadership, the implementation challenges identified earlier (regarding role clarity/ambiguity, professional identity, inter-professional relationships, organisational support and mentorship) have also been identified in other international reviews as key factors that influence ACPs' ability to enact their leadership capabilities. ${ }^{185}$ 195-198 Overall, in order to more fully understand the impact of ACP roles across all aspects of the health system, future research should focus on a more explicit investigation of the ACP role as an integration of activity/capability across the four pillars rather than examining one aspect in isolation.

Second, it was notable that much of the research related to the clinical pillar of the ACP role involved a direct comparison of ACP outcomes with other professions (mainly comparing ACPs with medical professionals, rather than comparing them with other cadres or levels of professionals). As such, the evidence base reflects a strong implicit assumption of the ACP role as a primarily clinical or medical substitution role, rather than a role with the potential to enhance, augment or transform services and skills mixes through innovating within a multi-professional team and bringing additional skills to bear associated with the cognate profession. Thus, in order to more fully understand the potential for transformational impacts across a whole service, there is a need to undertake research that examines the potential for ACPs to improve care above and beyond substitution for other professions. $^{199}$

Third, the review found that the majority of evidence reported on roles/services that were still relatively new ( $<2$ years). It is important to recognise therefore that most studies are reporting on the performance and skills of relatively 'novice' ACPs. This suggests that many studies and evaluations of the ACP role are taking place when the role is still in the relatively early stages and may not yet reflect the full picture of what ACPs can accomplish once they achieve a higher level of expertise and once the service is well established. As time goes on, one might expect experienced ACPs to deliver an even better or broader set of outcomes across the four pillars. It will be important for future research to include long-term evaluations that investigate the effect that 'service maturation' has on ACP outcomes and implementation, and to differentiate between novice and experienced practitioners. ${ }^{78} 200$ 


\section{Strengths and weaknesses of the review}

This was an exceptionally comprehensive review, examining the evidence on ACP roles/services in the UK across all settings, sectors and professions. As such, it provides a state-of-the art overview of ACP impacts, outcomes and role implementation challenges. The use of the international recognised PEPPA-Plus ${ }^{78}$ framework contributes to the development of an internationally transferable understanding of the factors influencing advanced practice role development, implementation and sustainability. The review was underpinned by a careful, comprehensive and systematic search strategy.

A potential weakness of the review is that the ambiguity and variability of ACP roles and titles means that some relevant studies may nonetheless have been missed or misclassified. In particular, there is ongoing ambiguity regarding the role of prescribing as a potential indicator of advanced clinical practice. The commissioned review requested the evaluation of the evidence base for advanced level practice beyond nursing, midwifery, allied health professions and pharmacy to include healthcare science, psychology, pharmacy, dental, social work, criminal justice and local authority. With such a broad range of professions, we took the view that qualifications such as non-medical prescribing could not be considered in isolation as a qualification representing advanced practice. Therefore, while for some professions such as nursing, independent prescribing is a critical component of advanced practice for others, such as social work, prescribing is not a requirement to practice at an advanced level.

\section{Recommendations}

The recommendations identified above are summarised in table 4 in terms of research, patient safety and engagement, and policy.

\section{CONCLUSION}

Due to government investment and current NHS policy imperatives, ACP is a rapidly evolving phenomenon in the UK, and it is likely that the snapshot of evidence presented in this report will quickly become out of date. Many of the challenges identified in this review are already being addressed (eg, through the educational governance process led by the Centre for Advancing Practice, through the development of sector-specific or setting-specific capability frameworks, ${ }^{188}$ and through role implementation toolkits ${ }^{201}$ ). Further innovations have emerged more recently as a response to the coronavirus pandemic. ${ }^{3}$ Going forward, it will be important to continue to evaluate, document and support this important area of health workforce development.

\footnotetext{
Author affiliations

${ }^{1}$ School of Health Sciences, University of Nottingham, Nottingham, UK

${ }^{2}$ School of Sociology and Social Policy, University of Nottingham, Nottingham, UK

${ }^{3}$ School of Education, University Hospitals Birmingham NHS Foundation Trust,

Birmingham, UK

${ }^{4}$ Faculty of Medicine and Health Sciences, University of Nottingham, Nottingham, UK
}

${ }^{5}$ School of Pharmacy, University of Nottingham, Nottingham, UK

${ }^{6}$ Emergency Department, Nottingham University Hospitals NHS Trust, Nottingham, UK

${ }^{7}$ Health Education England East Midlands, Leicester, UK

${ }^{8}$ College of Health, Medicine and Life Sciences, Brunel University London, Uxbridge, UK

${ }^{9}$ Centre for Advancing Practice, Health Education England, Leeds, UK

Twitter Catrin Evans @Catrin_notts

Contributors CE: coordinated and conceptualised the project. Developed all aspects of the project methodology and manuscript. Undertook key elements of the review. BP: reviewed and commented on the whole manuscript. Undertook all elements of the review. RP: conceptualised the project. Reviewed and commented on the whole manuscript. Assisted with study selection. Contributed to formulation of recommendations. JE: developed and implemented the search strategy. Reviewed and commented on the manuscript. PHendrick: reviewed and commented on the manuscript. Assisted with study selection. RK: reviewed and commented on the manuscript. Assisted with study selection. HB: reviewed and commented on the manuscript. Contributed to development of the methodological approach. Assisted with review of primary care sector data and formulation of recommendations. GY: reviewed and commented on the manuscript. Undertook some aspects of data extraction. JM: reviewed and commented on the manuscript. PT: reviewed and commented on the manuscript. Developed implications for non-traditional healthcare settings. RT: reviewed and commented on the manuscript. PHarris: reviewed and commented on the manuscript. JC: contributed to conceptualising the project. Reviewed and commented on the manuscript. Contributed to formulation of recommendations. RC: contributed to conceptualising the project. Reviewed and commented on the manuscript. Contributed to formulation of recommendations.

Funding This work was supported by Health Education England (DN384826Evaluation for HEE ACP Programme-Current Evidence Based for Advanced Level Practice within Health and Related Environments).

Competing interests RC is Clinical Lead for Musculoskeletal Practitioners in Primary Care and Lead of the Centre for Advancing Practice, Health Education England. JC is a Research Advisor to Health Education England.

Patient consent for publication Not required.

Provenance and peer review Not commissioned; externally peer reviewed.

Data availability statement All data relevant to the study are included in the article or uploaded as supplementary information.

Supplemental material This content has been supplied by the author(s). It has not been vetted by BMJ Publishing Group Limited (BMJ) and may not have been peer-reviewed. Any opinions or recommendations discussed are solely those of the author(s) and are not endorsed by BMJ. BMJ disclaims all liability and responsibility arising from any reliance placed on the content. Where the content includes any translated material, BMJ does not warrant the accuracy and reliability of the translations (including but not limited to local regulations, clinical guidelines, terminology, drug names and drug dosages), and is not responsible for any error and/or omissions arising from translation and adaptation or otherwise.

Open access This is an open access article distributed in accordance with the Creative Commons Attribution Non Commercial (CC BY-NC 4.0) license, which permits others to distribute, remix, adapt, build upon this work non-commercially, and license their derivative works on different terms, provided the original work is properly cited, appropriate credit is given, any changes made indicated, and the use is non-commercial. See: http://creativecommons.org/licenses/by-nc/4.0/.

\section{ORCID iDs}

Catrin Evans http://orcid.org/0000-0002-5338-2191

Joy Conway http://orcid.org/0000-0001-6464-1526

\section{REFERENCES}

1 Centre for Workforce Intelligence. In-depth review of the general practitioner workforce - final report, 2014. Available: https://assets. publishing.service.gov.uk/government/uploads/system/uploads/ attachment_data/file/507493/CfWI_GP_in-depth_review.pdf [Accessed 7 Dec 2019].

2 Imison C, Castle-Clarke S, Watson R. Reshaping the workforce to deliver the care patients need. London: Nuffield Trust, 2016. https:// 
www.nuffieldtrust.org.uk/research/reshaping-the-workforce-todeliver-the-care-patients-need

3 Health Education England. How did advanced clinical practitioners respond to COVID-19, 2020. Available: https://www.hee.nhs.uk/ coronavirus-covid-19/how-did-advanced-clinical-practitionersrespond-covid-19?s=09 [Accessed 27 Aug 2020].

4 NHS England. The NHS long term plan, 2019. Available: https:// www.longtermplan.nhs.uk/online-version/ [Accessed 8 Jul 2020].

5 NHS England. Interim NHS people plan, 2019. Available: https:// www.longtermplan.nhs.uk/wp-content/uploads/2019/05/InterimNHS-People-Plan_June2019.pdf [Accessed 1 Nov 2019].

6 NHS England. We are the NHS: people plan 2020/21 - action for us all, 2020. Available: https://www.england.nhs.uk/wp-content/ uploads/2020/07/We_Are_The_NHS_Action_For_us_all-1.pdf [Accessed 3 Aug 2020].

7 NHS England. Our people promise, 2020. Available: https://www. england.nhs.uk/ournhspeople/online-version/looking-after-ourpeople/our-nhs-people-promise/the-promise/ [Accessed 27 Aug 2020].

8 NHS England. General practice forward view, 2016. Available: https://www.england.nhs.uk/wp-content/uploads/2016/04/gpfv.pdf [Accessed 8 Jul 2020].

9 Scottish Government. Health and social care delivery plan, 2016. Available: https://www.gov.scot/binaries/content/documents/ govscot/publications/strategy-plan/2016/12/health-social-caredelivery-plan/documents/00511950-pdf/00511950-pdf/govscot\% 3Adocument/00511950.pdf [Accessed 13 Feb 2020].

10 NHS England. Integrated care systems, 2019. Available: https:// www.england.nhs.uk/integratedcare/integrated-care-systems/ [Accessed 19 Feb 2020].

11 NHS England. New care models: vanguards - developing a blueprint for the future of NHS and care services, 2016. Available: https://www.england.nhs.uk/wp-content/uploads/2015/11/new_ care_models.pdf

12 NHS Wales. NHS Wales planning framework 2020/23, 2020 Available: https://gov.wales/sites/default/files/publications/2019-09/ nhs-wales-planning-framework-2020-to-2023.pdf [Accessed 13 Feb 2020].

13 Bienkowska-Gibbs T, King S, Saunders C. New organisational models of primary care to meet the future needs of the NHS: a brief overview of recent reports. RAND Europe, 2015. Available: https:// www.rand.org/pubs/research_reports/RR1181.html [Accessed 08 Jul 2020].

14 Department of Health (Northern Ireland). Health and well being 2026: delivering together, 2019. Available: https://www.health-ni. gov.uk/sites/default/files/publications/health/progress-report-fulldocument.pdf [Accessed 13 Feb 2020]

15 Department of Health Social Services \& Public Safety (Northern Ireland). Advanced nursing practice framework: supporting advanced nursing practice in health and social care trusts, 2016. Available: https://www.health-ni.gov.uk/sites/default/files/ publications/health/advanced-nursing-practice-framework.pdf [Accessed 13 Feb 2020].

16 Gilburt H. Supporting integration through new roles and working across boundaries, 2016. Available: https://www.kingsfund.org. uk/publications/supporting-integration-new-roles-boundaries [Accessed 08 Jul 2020].

17 NHS Education for Scotland. Advanced practice toolkit, 2018 Available: http://www.advancedpractice.scot.nhs.uk/

18 NHS Wales. Framework for advanced nursing, midwifery and allied health professional practice in Wales. National leadership and innovation agency for healthcare (NLIAH), 2010. Available: https://www.wales.nhs.uk/sitesplus/documents/829/NLIAH\% 20Advanced\%20Practice\%20Framework.pdf [Accessed 13 Feb 2020].

19 Pierce E, Beling R. Advanced practitioner roles: relevance and sustainability in a 'liberated' NHS. Int Pract Dev J 2011;1:6.

20 de Bont A, van Exel J, Coretti S, et al. Reconfiguring health workforce: a case-based comparative study explaining the increasingly diverse professional roles in Europe. BMC Health Serv Res 2016;16:637.

21 Frenk J, Chen L, Bhutta ZA, et al. Health professionals for a new century: transforming education to strengthen health systems in an interdependent world. Lancet 2010;376:1923-58.

22 Buchan J, Campbell J. Challenges posed by the global crisis in the health workforce. BMJ 2013;347:f6201.

23 Salsberg E, Quigley L. Achieving sustainable and appropriately trained health and social care workers for ageing populations. In: Buchan J Dhillon I, Campbell J, eds. Health employment and economic growth: an evidence base. Geneva: World Health Organisation, 2017.

24 The Lancet. 2020: unleashing the full potential of nursing. Lancet 2019;394:1879.
25 WHO. Task shifting: rational redistribution of tasks among health workforce teams. Global recommendations and guidelines. Geneva: World Health Organisation, 2008.

26 WHO. Global strategy on human resources for health: workforce 2030, 2016. Available: https://www.who.int/hrh/resources/pub_globstrathrh2030/en/ [Accessed 13 Feb 2020].

27 Maier CB, Aiken LH. Task shifting from physicians to nurses in primary care in 39 countries: a cross-country comparative study. Eur J Public Health 2016;26:927-34.

28 Maier CB, Köppen J, Busse R, et al. Task shifting between physicians and nurses in acute care hospitals: cross-sectional study in nine countries. Hum Resour Health 2018;16:24.

29 Eaton G, Wong G, Williams V, et al. Contribution of paramedics in primary and urgent care: a systematic review. $\mathrm{Br} J$ Gen Pract 2020;70:e421-6.

30 Morris L, Moule P, Pearson J, et al. Patient views on the advanced practitioner role in primary care: a realist review. Physiotherapy 2019;105:e109.

31 Bentley M, Stirling C, Robinson A, et al. The nurse practitioner-client therapeutic encounter: an integrative review of interaction in aged and primary care settings. J Adv Nurs 2016;72:1991-2002.

32 Bonsall K, Cheater FM. What is the impact of advanced primary care nursing roles on patients, nurses and their colleagues? A literature review. Int J Nurs Stud 2008;45:1090-102.

33 Cardwell K, Smith SM. Clinical pharmacists working within family practice: what is the evidence? Fam Pract 2018;35:120-1.

34 Casey M, O'Connor L, Cashin A, et al. An overview of the outcomes and impact of specialist and advanced nursing and midwifery practice, on quality of care, cost and access to services: a narrative review. Nurse Educ Today 2017;56:35-40.

35 Cohen V, Jellinek SP, Hatch A, et al. Effect of clinical pharmacists on care in the emergency department: a systematic review. Am J Health Syst Pharm 2009;66:1353-61.

36 Desmeules F, Roy J-S, MacDermid JC, et al. Advanced practice physiotherapy in patients with musculoskeletal disorders: a systematic review. BMC Musculoskelet Disord 2012;13:107.

37 Donald F, Martin-Misener R, Carter N, et al. A systematic review of the effectiveness of advanced practice nurses in long-term care. $J$ Adv Nurs 2013;69:2148-61.

38 Evans R, McGovern R, Birch J, et al. Which extended paramedic skills are making an impact in emergency care and can be related to the UK paramedic system? A systematic review of the literature. Emerg Med J 2014;31:594-603.

39 Ferreira GE, Traeger AC, O'Keeffe M, et al. Staff and patients have mostly positive perceptions of physiotherapists working in emergency departments: a systematic review. J Physiother 2018:64:229-36.

40 Hardy M, Johnson L, Sharples R, et al. Does radiography advanced practice improve patient outcomes and health service quality? A systematic review. Br J Radiol 2016;89:1062.

41 Harrison-Blount M, Nester C, Williams A. The changing landscape of professional practice in podiatry, lessons to be learned from other professions about the barriers to change - a narrative review. J Foot Ankle Res 2019;12:23.

42 Jakimowicz M, Williams D, Stankiewicz G. A systematic review of experiences of advanced practice nursing in general practice. $B M C$ Nurs 2017:16:6

43 Jebara T, Cunningham S, MacLure K, et al. Stakeholders' views and experiences of pharmacist prescribing: a systematic review. $\mathrm{Br} J$ Clin Pharmacol 2018;84:1883-905.

44 Jokiniemi K, Pietilä A-M, Kylmä J, et al. Advanced nursing roles: a systematic review. Nurs Health Sci 2012;14:421-31.

45 Kanda M, Ota E, Fukuda H, et al. Effectiveness of communitybased health services by nurse practitioners: protocol for a systematic review and meta-analysis. BMJ Open 2015;5:e006670.

46 Kersten P, McPherson K, Lattimer V, et al. Physiotherapy extended scope of practice - who is doing what and why? Physiotherapy 2007;93:235-42.

47 Laurant M, van der Biezen M, Wijers N, et al. Nurses as substitutes for doctors in primary care. Cochrane Database Syst Rev 2018;7:CD001271.

48 McPherson K, Kersten P, George S, et al. A systematic review of evidence about extended roles for allied health professionals. $J$ Health Serv Res Policy 2006;11:240-7.

49 Moran GM, Nairn S. How does role transition affect the experience of trainee advanced clinical practitioners: qualitative evidence synthesis. J Adv Nurs 2018;74:251-62.

50 Saxon RL, Gray MA, Oprescu FI. Extended roles for allied health professionals: an updated systematic review of the evidence. J Multidiscip Healthc 2014;7:479-88. 
51 Simmance N, Cortinovis T, Green C, et al. Introducing novel advanced practice roles into the health workforce: dietitians leading in gastrostomy management. Nutr Diet 2019;76:14-20.

52 Thom SE. Does advanced practice in radiography benefit the healthcare system? A literature review. Radiography 2018;24:84-9.

53 Thompson J, Yoward S, Dawson P. The role of physiotherapy extended scope practitioners in musculoskeletal care with focus on decision making and clinical outcomes: a systematic review of quantitative and qualitative research. Musculoskeletal Care 2017;15:91-103.

54 Turner J, Coster J, Chambers D, et al. What evidence is there on the effectiveness of different models of delivering urgent care? A rapid review. Health Serv Deliv Res 2015;3:1-134.

55 Williams K. Advanced practitioners in emergency care: a literature review. Emerg Nurse 2017;25:36-41.

56 Delamaire M, Lafortune G. Nurses in advanced roles: a description and evaluation of experiences in 12 developed countries. OECD Health Working Papers 2010;54.

57 King R, Tod A, Sanders T. Development and regulation of advanced nurse practitioners in the UK and internationally. Nurs Stand 2017;32:43-50.

58 Leary A, MacLaine K. The evolution of advanced nursing practice: past, present and future. Nurs Times 2019;115:18-19 https://www. nursingtimes.net/roles/specialist-nurses/evolution-advancednursing-practice-past-present-future-10-09-2019/

59 East L, Knowles K, Pettman M, et al. Advanced level nursing in England: organisational challenges and opportunities. J Nurs Manag 2015;23:1011-9.

60 Leary A, Maclaine K, Trevatt P, et al. Variation in job titles within the nursing workforce. J Clin Nurs 2017;26:4945-50.

61 Lawler J, Maclaine K, Leary A. Workforce experience of the implementation of an advanced clinical practice framework in England: a mixed methods evaluation. Hum Resour Health 2020;18:96.

62 British Medical Association (BMA). New clinical roles in the UK, 2020. Available: https://www.bma.org.uk/advice-and-support/nhsdelivery-and-workforce/workforce/new-clinical-roles-in-the-nhs [Accessed 8 Jul 2020].

63 Council of Deans for Health. Advanced clinical practice education in England: event report from the 2018 Council of deans of Health/ Health education England advanced clinical practice education conference, 2018. Available: https://councilofdeans.org.uk/ wp-content/uploads/2018/11/081118-FINAL-ACP-REPORT.pdf [Accessed 08 Jul 2020].

64 Dover N, Lee GA, Raleigh M, et al. A rapid review of educationa preparedness of advanced clinical practitioners. J Adv Nurs 2019;75:3210-8.

65 Health Education England. Multi-professional framework for advanced clinical practice in England, 2017. Available: https://www hee.nhs.uk/our-work/advanced-clinical-practice/multi-professionalframework [Accessed 8 Jul 2020].

66 NHS Employers. Advanced clinical practice, 2019. Available: https://www.nhsemployers.org/your-workforce/plan/workforcesupply/education-and-training/advanced-clinical-practice [Accessed 1 Nov 2019].

67 Peters MDJ, Godfrey C, Mclnerney P. Chapter 11: Scoping reviews (2020 version). In: Aromataris E, Munn Z, eds. JBI manual for evidence synthesis. Joanna Briggs Institute, 2020. https:// synthesismanual.jbi.global

68 Peters MDJ, Marnie C, Tricco AC, et al. Updated methodological guidance for the conduct of scoping reviews. JBI Evid Synth 2020;18:2119-26.

69 Khalil H, Peters MD, Tricco AC, et al. Conducting high quality scoping reviews-challenges and solutions. J Clin Epidemiol 2021;130:156-60.

70 Evans C, Poku B, Pearce R. Characterising the evidence base for advanced clinical practice in the UK: a scoping review. Open science framework (registries), 2019. Available: https://osf.io/tzpe5 [Accessed 6 Nov 2019].

71 Evans C, Poku B, Pearce R, et al. Characterising the evidence base for advanced clinical practice in the UK: a scoping review protocol. BMJ Open 2020;10:e036192.

72 Tricco AC, Lillie E, Zarin W, et al. PRISMA extension for scoping reviews (PRISMA-ScR): checklist and explanation. Ann Intern Med 2018;169:467-73

73 Ayiku L, Levay P, Hudson T, et al. The Medline UK filter: development and validation of a geographic search filter to retrieve research about the UK from OVID Medline. Health Info Libr J 2017:34:200-16.
74 Ayiku L, Levay P, Hudson T, et al. The Embase UK filter: validation of a geographic search filter to retrieve research about the UK from OVID Embase. Health Info Libr J 2019;36:121-33.

75 Carroll C, Booth A, Leaviss J, et al. "Best fit" framework synthesis: refining the method. BMC Med Res Methodol 2013;13.

76 Bryant-Lukosius D, Callens B, De Geest S. Advanced nursing practice roles in Switzerland: a proposed framework for evaluation. Basel, Switzerland: Institute of Nursing Science, University of Basel, 2015. https://pdfs.semanticscholar.org/c2b7/d292ae31bf22 eebba12f42d9ac2179f0edbb.pdf?_ga=2.87696792.1641364989. 1594307205-1902281963.1594307205

77 Bryant-Lukosius D, Dicenso A. A framework for the introduction and evaluation of advanced practice nursing roles. J Adv Nurs 2004;48:530-40.

78 Bryant-Lukosius D, Spichiger E, Martin J, et al. Framework for evaluating the impact of advanced practice nursing roles. J Nurs Scholarsh 2016;48:201-9.

79 Braun V, Clarke V. Using thematic analysis in psychology. Qual Res Psychol 2006;3:77-101.

80 QSR NVivo 12 Pro. Available: https://www.qsrinternational.com/ nvivo-qualitative-data-analysis-software/home [Accessed 14 Dec 2020].

81 Moher D, Liberati A, Tetzlaff J, et al. Preferred reporting items for systematic reviews and meta-analyses: the PRISMA statement. $J$ Clin Epidemiol 2009;62:1006-12.

82 Wallymahmed ME, Morgan C, Gill GV, et al. Nurse-led cardiovascular risk factor intervention leads to improvements in cardiovascular risk targets and glycaemic control in people with type 1 diabetes when compared with routine diabetes clinic attendance. Diabet Med 2011;28:373-9.

83 McClellan CM, Cramp F, Powell J, et al. A randomised trial comparing the clinical effectiveness of different emergency department healthcare professionals in soft tissue injury management. BMJ Open 2012;2:e001092.

84 Bruhn $\mathrm{H}$, Bond CM, Elliott AM, et al. Pharmacist-led management of chronic pain in primary care: results from a randomised controlled exploratory trial. BMJ Open 2013;3:e002361.

85 Bruhn H, Bond CM, Elliott A. Pharmacist-led management of chronic pain in primary care: the PIPPC study. Int J Pharm Pract 2011;19:22-3.

86 Neilson AR, Bruhn $\mathrm{H}$, Bond $\mathrm{CM}$, et al. Pharmacist-led management of chronic pain in primary care: costs and benefits in a pilot randomised controlled trial. BMJ Open 2015;5:e006874.

87 Donnelly R, Hughes CM, Harper R. A feasibility study of pharmacist independent prescribing in a primary care setting. Diabet Med 2010;27:165.

88 Inch J, Notman F, Bond CM, et al. The care home independent prescribing pharmacist study (CHIPPS)-a non-randomised feasibility study of independent pharmacist prescribing in care homes. Pilot Feasibility Stud 2019;5:89.

89 Abutaleb M, Steinke D, Williams S. Effectiveness of independent pharmacist prescribers in glycaemic control of type 2 diabetes. Pharmacotherapy 2015;35:e243.

90 Abbas Y, Smith G, Trinidade A. Audiologist-led screening of acoustic neuromas in patients with asymmetrical sensorineural hearing loss and/or unilateral tinnitus: our experience in 1126 patients. J Laryngol Otol 2018;132:786-9.

91 Barton D, Mashlan W. An advanced nurse practitioner-led service consequences of service redesign for managers and organizational infrastructure. J Nurs Manag 2011;19:943-9.

92 Brealey S, King DG, Hahn S. The costs and effects of introducing selectively trained radiographers to an A\&E reporting service: a retrospective controlled before and after study. $\mathrm{Br} J$ Radiol 2005;78:499-505.

93 Brealey SD, King DG, Hahn S, et al. Radiographers and radiologists reporting plain radiograph requests from accident and emergency and general practice. Clin Radiol 2005;60:710-7.

94 Brealey SD, Scuffham PA. The effect of introducing radiographer reporting on the availability of reports for accident and emergency and general practitioner examinations: a time-series analysis. $\mathrm{Br}$ Radiol 2005;78:538-42.

95 Candy E, Haworth-Booth S, Knight-Davis M. Review of the effectiveness of a consultant Physiotherapy-Led musculoskeletal interface team: a Welsh experience. Musculoskeletal Care 2016;14:185-91.

96 Denton G. External transfer of invasively ventilated patients by advanced critical care practitioners. J Intensive Care Soc 2019;20:45-6.

97 Denton G, Arora N, Choyce A. Transfer of ventilated critically ill patients by advanced critical care practitioners. J Intensive Care Soc 2018;19:60. 
98 Denton G, Arora N, Palmer M. Can advanced critical care practitioners provide safe advanced airway management? J Intensive Care Soc 2018;19:133

99 Denton G, Green L, Palmer M, et al. The provision of central venous access, transfer of critically ill patients and advanced airway management.: are advanced critical care practitioners safe and effective? J Intensive Care Soc 2019;20:248-54.

100 Fox N, Tuck J, Chandler J, et al. Advanced nurse practitioner-led ambulatory care for older people: safe and effective. Age Ageing 2017:46:11-22.

101 Gregory H, Treece S. Improving patient experience for palliative radiotherapy: a consultant Radiographer led pathway. Clin Oncol 2018;30:S9-10.

102 Hall D, Wilkinson AR. Quality of care by neonatal nurse practitioners: a review of the Ashington experiment. Arch Dis Child Fetal Neonatal Ed 2005;90:F195-200.

103 Judson EE, Nightingale JM. An evaluation of radiographer performed and interpreted barium swallows and meals. Clin Radiol 2009;64:807-14.

104 Kneebone R, Nestel D, Chrzanowska J, et al. The perioperative specialist practitioner: developing and evaluating a new surgical role. Qual Saf Health Care 2006;15:354-8.

105 Payton H, Jaques N, Lacey F. Evaluating the clinical impact of a pharmacist-led diabetes outpatient clinic. Int J Pharm Pract 2011:19:17.

106 Pottle A. A nurse-led rapid access chest pain clinic - Experience from the first 3 years. Eur J Cardiovasc Nurs 2005;4:227-33.

107 Ryan S, Packham JC, T Dawes P, et al. The impact of a nurseled chronic musculoskeletal pain clinic on healthcare utilization. Musculoskeletal Care 2012;10:196-201.

108 Tan M, Menon S, Black D. The impact on patients of a nurse-led clinical service in gastroenterology. Br J Nurs 2017;26:734-8.

109 Anderson H, Birks Y, Adamson J. Exploring the relationship between nursing identity and advanced nursing practice: an ethnographic study. J Clin Nurs 2019;29:1195-208.

110 Barratt J, Thomas N. Nurse practitioner consultations in primary health care: an observational interaction analysis of social interactions and consultation outcomes. Prim Health Care Res Dev 2019:20:e37.

111 Collins D. Assessing the effectiveness of advanced nurse practitioners undertaking home visits in an out of hours urgent primary care service in England. J Nurs Manag 2019;27:450-8.

112 Cousins R, Donnell C. Nurse prescribing in general practice: a qualitative study of job satisfaction and work-related stress. Fam Pract 2012;29:223-7.

113 Griffiths S, Taylor C, Yohannes AM. Conversion rates and perceived barriers to referral: views of extended scope physiotherapists in the primary care setting. Musculoskeletal Care 2012:10:221-31.

114 Hensman-Crook A. Advanced physiotherapy in primary care. part of the solution for a growing crisis? Physiotherapy 2017;103:e112

115 McMurray R. The struggle to professionalize: an ethnographic account of the occupational position of advanced nurse practitioners. Hum Relat 2011;64:801-22.

116 Redsell SA, Jackson C, Stroke T. Patient expectations of 'firstcontact care' consultations with nurse and general practitioners in primary care. Quality in Primary Care 2007:15:5-10

117 Ross J, McGowan S, Wightman N. Advanced practitioner physiotherapist as 1st point of contact in a GP cluster in Lanarkshire. Physiotherapy 2019;105:e96.

118 Thompson J, McNall A, Tiplady S. Whole systems approach: advanced clinical practitioner development and identity in primary care. J Healthc Org Manage 2019;33:443-59.

119 Williams V, Smith A, Chapman L, et al. Community matrons-an exploratory study of patients' views and experiences. J Adv Nurs 2011;67:86-93.

120 Anderson C. Leadership experience of London-based advanced nurse practitioners (ANP): a case study analysis. PhD Thesis; United Kingdom: University College London, 2017. Available: http:// discovery.ucl.ac.uk/1569291/ [Accessed 1 Jul 2020].

121 Booth J, Hutchison C, Beech C, et al. New nursing roles: the experience of Scotland's consultant nurse/midwives. J Nurs Manag 2006:14:83-9.

122 Mullen C, Gavin-Daley A, Kilgannon H, et al. Nurse consultants 10 years on: an insight to the role for nurse managers. J Nurs Manag 2011;19:820-31.

123 Stevenson K, Ryan S, Masterson A. Nurse and allied health professional consultants: perceptions and experiences of the role. $J$ Clin Nurs 2011;20:537-44.

124 Walsgrove H. Exploration of advanced nursing in a hospital context : people, processes, frameworks. DProf; United Kingdom:
Bournemouth University, 2019. http://eprints.bournemouth.ac.uk/ 32706/

125 Woodward VA, Webb C, Prowse M. Nurse consultants: their characteristics and achievements. J Clin Nurs 2005;14:845-54.

126 Woodward VA, Webb C, Prowse M. Nurse consultants: organizational influences on role achievement. J Clin Nurs 2006:15:272-80.

127 Pearse EO, Maclean A, Ricketts DM. The extended scope physiotherapist in orthopaedic out-patients - an audit. Ann R Coll Surg Engl 2006;88:653-5.

128 Reeve S, May S. Exploration of patients' perspectives of quality within an extended scope physiotherapists' spinal screening service. Physiother Theory Pract 2009;25:533-43.

129 Gladman JRF, Chikura G. Nurse practitioners in UK care homes. Medical crises in older people: discussion paper series, 2011. Available: https://www.nottingham.ac.uk/mcop/documents/papers/ issue8-mcop-issn2044-4230.pdf [Accessed 1 Jul 2020].

130 Hoddes R, Hattab A, England A. Initial single centre experiences of a radiographer advanced practitioner led nephrostomy exchange programme. Radiography 2020;26:163-6.

131 Sidhu SK, Davies E, Mcwhirter K, et al. The effects of introducing a nurse led ascitic drain insertion service. J Hepatol 2014;60:S230.

132 Redwood S, Lloyd H, Carr E, et al. Evaluating nurse consultants' work through key informant perceptions. Nurs Stand 2007;21:35-40.

133 Robinson A. The role of consultant midwife: An exploration of the expectations, experiences and intricacies. PhD Thesis; United Kingdom: University of Southampton, 2012. Available: https:// eprints.soton.ac.uk/349088/1/Final\%2520Thesis.pdf [Accessed 29 Jun 2020].

134 Charters S, Knight S, Currie J, et al. Learning from the past to inform the future-a survey of consultant nurses in emergency care. Accid Emerg Nurs 2005;13:186-93.

135 McDonnell A, Goodwin E, Kennedy F, et al. An evaluation of the implementation of advanced nurse practitioner (ANP) roles in an acute hospital setting. J Adv Nurs 2015;71:789-99.

136 Skinner H, Skoyles J, Redfearn S, et al. Advanced care nurse practitioners can safely provide sole resident cover for level three patients: impact on outcomes, cost and work patterns in a cardiac surgery programme. Eur $J$ Cardiothorac Surg 2013;43:19-22.

137 Davies J, Bickell F, Tibby SM. Attitudes of paediatric intensive care nurses to development of a nurse practitioner role for critical care transport. J Adv Nurs 2011;67:317-26.

138 Miller R, Darcy C, Friel A. The introduction of a new consultant pharmacist case management service on the care of elderly patients in the intermediate care setting. Int $J$ Pharm Pract 2014;22:105-6.

139 Walumbe J. Working with complex persistent pain: the role of the advanced physiotherapy practitioner in an acute hospital setting. Physiotherapy 2017;103:e30.

140 Bush J, Langley CA, Jenkins D, et al. Clinical pharmacists in general practice: an initial evaluation of activity in one English primary care organisation. Int J Pharm Pract 2018;26:501-6.

141 Pallan M, Linnane J, Ramaiah S. Evaluation of an independent, radiographer-led community diagnostic ultrasound service provided to general practitioners. J Public Health 2005;27:176-81.

142 Scottish School of Primary Care. Evaluation of new models of primary care: Inverclyde case study, 2018. Available: http://www. sspc.ac.uk/media/media_573766_en.pdf [Accessed 1 Jul 2020].

143 Akehurst N, Bamford S, Brooks E. A specialist led back pain service in primary care. advanced practice physiotherapists (APP) working as first contact practitioners (FCPs). Physiotherapy 2019;105:e100.

144 Goodwin RW, Hendrick PA. Physiotherapy as a first point of contact in general practice: a solution to a growing problem? Prim Health Care Res Dev 2016;17:489-502.

145 Horne L, Slade V, Evans A. Transformation of MSK services in Halton Cheshire to first contact practitioner model. Physiotherapy 2019;105:e107.

146 Parfitt N, Smeatham A, Timperley J, et al. Direct listing for total hip replacement (Thr) by primary care physiotherapists. Clin Govern Int $J$ 2012;17:210-6.

147 Cuthbertson LM. Skeletal trauma reporting; perceptions and experiences of radiographer practitioners exposed to the reporting role. Radiography 2020;26:35-41.

148 Dalton MA. Perceptions of the advanced nurse practitioner role in a hospital setting. Br J Nurs 2013:22:48-53.

149 Halliday S, Hunter DJ, McMillan L. Ward staff perceptions of the role of the advanced nurse practitioner in a 'hospital at day' setting. $\mathrm{Br} J$ Nurs 2018;27:92-7. 
150 Harris R, Paterson A. Exploring the research domain of consultant practice: experiences of consultant radiographers. Radiography 2016;22:e25-33.

151 Henwood S, Booth L. On becoming a consultant: a study exploring the journey to consultant practice. Radiography 2016;22:32-7.

152 Henwood S, Booth L, Miller PK. Reflections on the role of consultant radiographers in the UK: the perceived impact on practice and factors that support and hinder the role. Radiography 2016;22:44-9.

153 Kalra N, Solanki SP, Tyagi AK. Advanced nurse practitioners and junior neurosurgery trainees-a truly symbiotic relationship? $\mathrm{Br} J$ Neurosurg 2018;32:332.

154 McSherry R, Mudd D, Campbell S. Evaluating the perceived role of the nurse consultant through the lived experience of healthcare professionals. J Clin Nurs 2007;16:2066-80.

155 Rees Z. Consultant breast radiographers: where are we now?: an evaluation of the current role of the consultant breast radiographer. Radiography 2014;20:121-5.

156 Seneviratne RE, Bradbury H, Bourne RS. How do pharmacists develop into advanced level practitioners? learning from the experiences of critical care pharmacists. Pharmacy 2017;5:38.

157 Williamson S, Twelvetree T, Thompson J, et al. An ethnographic study exploring the role of ward-based advanced nurse practitioners in an acute medical setting. $J$ Adv Nurs 2012;68:1579-88

158 Anderson $\mathrm{H}$. Professional identity and the advanced nurse practitioner in primary care: a qualitative study. $\mathrm{PhD}$ Thesis; United Kingdom: University of York, 2017. Available: http://etheses. whiterose.ac.uk/17287/ [Accessed 1 Jul 2020].

159 Barratt J, Thomas N. Nurse practitioner consultations in primary health care: patient, carer, and nurse practitioner qualitative interpretations of communication processes. Prim Health Care Res Dev 2018;20:e47.

160 Barratt J, Thomas N. Nurse practitioner consultations in primary health care: a case study-based survey of patients' pre-consultation expectations, and post-consultation satisfaction and enablement. Prim Health Care Res Dev 2019;20:e36.

161 Crumbie A. A nurse practitioner's tale: an autoethnographic interpretive study of the values of nurse practitioners, general practitioners and district nurses. DNSc; United Kingdom: Swansea University, 2005. Available: http://cronfa.swan.ac.uk/Record/ cronfa42455 [Accessed 2 Dec 19]

162 Gerard K, Tinelli M, Latter S, et al. Valuing the extended role of prescribing pharmacist in general practice: results from a discrete choice experiment. Value Health 2012;15:699-707.

163 Hall JP. Nurse practitioners' perceptions of their role and value in UK general practice. DProf; United Kingdom: Sheffield Hallam University, 2016. Available: http://shura.shu.ac.uk/14749/ [Accessed 2 Dec 2019].

164 Main R, Dunn N, Kendall K. 'Crossing professional boundaries' barriers to the integration of nurse practitioners in primary care. Educ Prim Care 2007;18:480-7.

165 Mann C, Anderson C, Avery AJ. Clinical pharmacists in general practice: pilot scheme. University of Nottingham, 2018. https:// www.england.nhs.uk/commissioning/wp-content/uploads/sites/12/ 2015/07/clinical-pharmacists-gp-pilot.pdf

166 Moffatt F, Goodwin R, Hendrick P. Physiotherapy-as-first-pointof-contact-service for patients with musculoskeletal complaints: understanding the challenges of implementation. Prim Health Care Res Dev 2018;19:121-30.

167 Mullen R, Merriman M, Morecroft WC. Clinical pharmacists in general practice pilot: Semi-structured interviews to explore GP and pharmacist perspectives. Int J Pharm Pract 2018;26:18.

168 Nabhani-Gebara S, Fletcher S, Shamim A, et al. General practice pharmacists in England: integration, mediation and professional dynamics. Res Social Adm Pharm 2020;16:17-24.

169 Nelson PA, Bradley F, Martindale A-M, et al. Skill-mix change in general practice: a qualitative comparison of three 'new' non-medical roles in English primary care. Br J Gen Pract 2019;69:e489-98.

170 Oliver E. Driving the role of the advanced practitioner in primary care. Pract Nurs 2017;28:42-5.

171 Paniagua H. Advanced nurse practitioners and GPs: what is the difference? Pract Nurs 2011;22:383-8.

172 Perry C, Thurston M, Killey M, et al. The nurse practitioner in primary care: alleviating problems of access? Br J Nurs 2005;14:255-9.

173 Raleigh M, Allan H. A qualitative study of advanced nurse practitioners' use of physical assessment skills in the community: shifting skills across professional boundaries. J Clin Nurs 2017:26:2025-35.
174 Redsell S, Stokes T, Jackson C, et al. Patients' accounts of the differences in nurses' and general practitioners' roles in primary care. J Adv Nurs 2007;57:172-80.

175 Yuill J. The role and experiences of advanced nurse practitioners working in out of hours urgent care services in a primary care setting. Nurs Manage 2018;25:18-23.

176 Brimblecombe N, Nolan F, Khoo M-E, et al. The nurse consultant in mental health services: a national, mixed methods study of an advanced practice role. J Psychiatr Ment Health Nurs 2019;26:117-30.

177 Jones A, Powell T, Watkins D, et al. Realising their potential? Exploring interprofessional perceptions and potential of the advanced practitioner role: a qualitative analysis. BMJ Open 2015;5:e009740.

178 Bruhn $\mathrm{H}$, Bond CM, Elliott AM, et al. Pharmacist-led management of chronic pain in primary care: results from a randomised controlled exploratory trial. BMJ Open 2013;3 doi:10.1136/ bmjopen-2012-002361

179 NHS Education for Scotland. Ahp advanced practice framework (mental health), 2014. Available: https://www.nes.scot.nhs.uk/ media/2588985/ahp_advanced_practice_framework_mental_heath 2014_02.pdf [Accessed 27 Aug 2020].

180 Goemaes R, Beeckman D, Goossens J, et al. Advanced midwifery practice: an evolutionary concept analysis. Midwifery 2016;42:29-37.

181 Hyde R, MacVicar S, Humphrey T. Advanced practice for children and young people: a systematic review with narrative summary. $J$ Adv Nurs 2020;76:135-46.

182 Crouch R, Brown R. Advanced clinical practitioners in emergency care: past, present and future. Br J Hosp Med 2018;79:511-5.

183 Bigham BL, Kennedy SM, Drennan I, et al. Expanding paramedic scope of practice in the community: a systematic review of the literature. Prehosp Emerg Care 2013;17:361-72.

184 Martínez-González NA, Djalali S, Tandjung R, et al. Substitution of physicians by nurses in primary care: a systematic review and meta-analysis. BMC Health Serv Res 2014;14:214-14.

185 Spacey A, Hipperson V, Gloster A, et al. The role of the advanced clinical practitioner in breast diagnosis: a systematic review of the literature. Radiography 2021;27:654-62.

186 Weeks G, George J, Maclure K, et al. Non-medical prescribing versus medical prescribing for acute and chronic disease management in primary and secondary care. Cochrane Database Syst Rev 2016;11:CD011227.

187 Tsiachristas A, Wallenburg I, Bond CM, et al. Costs and effects of new professional roles: evidence from a literature review. Health Policy 2015;119:1176-87.

188 Health Education England. Core capabilities framework for advanced clinical practice (nurses) working in general practice / primary care in England, 2020. Available: https://www.hee.nhs. uk/sites/default/files/documents/ACP\%20Primary\%20Care\% 20Nurse\%20Fwk\%202020.pdf [Accessed 8 Aug 2020].

189 The Faculty of Intensive Care Medicine. Advanced critical care practitioners (ACCPs). Available: https://www.ficm.ac.uk/trainingexaminations/accps [Accessed 27 Aug 2020].

190 Karimi-Shahanjarini A, Shakibazadeh E, Rashidian A, et al. Barriers and facilitators to the implementation of doctor-nurse substitution strategies in primary care: a qualitative evidence synthesis. Cochrane Database Syst Rev 2019;4:CD010412.

191 Torrens C, Campbell P, Hoskins G, et al. Barriers and facilitators to the implementation of the advanced nurse practitioner role in primary care settings: a scoping review. Int J Nurs Stud 2020;104:103443

192 Greenhalgh T, Papoutsi C. Studying complexity in health services research: desperately seeking an overdue paradigm shift. BMC Med 2018;16:95.

193 Long KM, McDermott F, Meadows GN. Being pragmatic about healthcare complexity: our experiences applying complexity theory and pragmatism to health services research. BMC Med 2018;16:94

194 Shiell A, Hawe P, Gold L. Complex interventions or complex systems? Implications for health economic evaluation. $B M J$ 2008:336:1281-3

195 Elliott N. Building leadership capacity in advanced nurse practitioners - the role of organisational management. J Nurs Manag 2017;25:77-81.

196 Elliott N, Begley C, Kleinpell R, et al. The development of leadership outcome-indicators evaluating the contribution of clinical specialists and advanced practitioners to health care: a secondary analysis. $J$ Adv Nurs 2014:70:1078.

197 Elliott N, Begley C, Sheaf G, et al. Barriers and enablers to advanced practitioners' ability to enact their leadership role: a scoping review. Int J Nurs Stud 2016;60:24-45. 
198 Elliott N, Higgins A, Begley C, et al. The identification of clinical and professional leadership activities of advanced practitioners: findings from the specialist clinical and advanced practitioner evaluation study in Ireland. J Adv Nurs 2013;69:1037-50.

199 Mason S. A pragmatic quasi-experimental multi-site community intervention trial evaluating the impact of emergency care practitioners in different UK health settings on patient pathways (NEECaP trial). Emerg Med J 2013;29.

200 Brooten D, Youngblut JM, Deosires W, et al. Global considerations in measuring effectiveness of advanced practice nurses. Int $J$ Nurs Stud 2012;49:906-12.

201 Health Education England. Muskuloskeletal first contact practitioner services: implementation guide, 2020. Available: https://www.hee.nhs.uk/sites/default/files/documents/FCP\% 20How\%20to\%20Guide\%20v21\%20040919\%20-\%202.pdf [Accessed 8 Jul 2020].

202 Alexander S, Hopkins N, Lalondrelle S, et al. Implementation of Radiographer-Led image-guided radiotherapy (IGRT) for cervix cancer. Clin Oncol 2018;30:S2-3.

203 Allan C, Gibson L, Rice L. Conversion rates of patients referred, via advanced physiotherapy practitioners, to a spinal consultant post MRI scanning. Eur Spine J 2012;21:S267.

204 Avery L, Butler J. An evaluation of the role of diabetes nurse consultants in the UK. J Diabetes Nurs 2008;12:58-63 https://www. woundsinternational.com/uploads/resources/dotn/ master/552/ files/pdf/jdn12-2pg58596263.pdf

205 Bendle M, Samani A, Newsom-Davis T. Independent prescribing pharmacist clinics; how they can benefit oncology services. Lung Cancer 2017;103:S46-7.

206 Bradley AJ, Rajashanker B, Atkinson SL, et al. Accuracy of reporting of intravenous urograms: a comparison of radiographers with radiology specialist registrars. Clin Radiol 2005;60:807-11.

207 Brealey S, Piper K, King D, et al. Observer agreement in the reporting of knee and lumbar spine magnetic resonance (MR) imaging examinations: selectively trained MR radiographers and consultant radiologists compared with an index radiologist. Eur $J$ Radiol 2013;82:e597-605.

208 Brown J, Bonnington D, Shokuhi S, et al. Advanced nurse practitioners - new roles and outcomes in symptomatic breast clinic. Eur J Surg Oncol 2015;41:S26.

209 Buckley H, Bradshaw K, Gregory D, et al. Audit of radiographerled service for adjuvant vaginal vault brachytherapy without image guidance in early endometrial cancer. Clin Oncol 2018;30:S3.

210 Burling D, Wylie P, Gupta A, et al. CT colonography: accuracy of initial interpretation by radiographers in routine clinical practice. Clin Radiol 2010;65:126-32.

211 Burrows L, Lesser TH, Kasbekar AV, et al. Independent prescriber physiotherapist led balance clinic: the Southport and Ormskirk pathway. J Laryngol Otol 2017;131:417-24.

212 Cowley A, Cooper J, Goldberg S. Experiences of the advanced nurse practitioner role in acute care. Nurs Older People 2016;28:31-6.

213 Diver C, Bhatia P, Smart J, et al. Creating additional clinic capacity in new lung cancer clinics by use of an advanced nurse practitioner. Lung Cancer 2014;83:S40.

214 Duncan N. Evaluating a pharmacist prescriber role in haematology and oncology clinics. J Oncol Pharm Pract 2017;23:25.

215 Fish S. Pilot of an advanced practitioner physiotherapist to improve the triage process and assess patients with non-inflammatory conditions in rheumatology. Physiotherapy 2019;105:e79.

216 Ford $\mathrm{P}$. The role of the consultant radiographer - experience of appointees. Radiography 2010;16:189-97.

217 Gallagher M-J. Introduction of a nurse-led intravitreal injection service in ophthalmology. Br J Nurs 2017;26:800-3.

218 Glendinning A, Walker D. Advanced nurse practitioners; what do the team think? Future Healthc J 2019;6:1.

219 Goldfinch R, Allerton R, Khanduri S, et al. The impact of the introduction of a palliative Macmillan consultant radiographer at one UK cancer centre. Br J Radiol 2016;89:20160286.

220 Gregorowski A, Brennan E, Chapman S, et al. An action research study to explore the nature of the nurse consultant role in the care of children and young people. J Clin Nurs 2013;22:201-10.

221 Heywood JW. Specialist physiotherapists in orthopaedic triagethe results of a military spinal triage clinic. J R Army Med Corps 2005;151:152-6.

222 Horne J, Green B. Assessing the quality of colorectal cancer reporting by an advanced practitioner healthcare scientist. $J$ Pathol 2013;231:S38.

223 Hyde R. An advanced nurse practitioner service for neonates, children and young people. Nurs Child Young People 2017;29:36-41.
224 Jackson A, Carberry M. The advance nurse practitioner in critical care: a workload evaluation. Nurs Crit Care 2015;20:71-7.

225 Kennedy C, Brooks Young P, Nicol J, et al. Fluid role boundaries: exploring the contribution of the advanced nurse practitioner to multi-professional palliative care. J Clin Nurs 2015;24:3296-305.

226 Lane L, Minns S. Empowering advanced practitioners to set up nurse led clinics for improved outpatient care. Nurs Times 2010;106:14-15 https://www.nursingtimes.net/download?ac= 1258737

227 Lauren W, Trudi M. A study exploring the opinions and attitudes of medical staff towards pharmacist independent prescribing in a neonatal intensive care unit. Arch Dis Child 2018;103:e1

228 Lilley A. Are parents and patients happy to see an advanced paediatric pharmacist practitioner (APPP)? Arch Dis Child 2019;104:e2

229 Lockwood P, Piper K. AFROC analysis of reporting radiographer's performance in CT head interpretation. Radiography 2015;21:e90-5.

230 Marriage D, Kanchanatheera M, Thursby-Pelham A. Parental satisfaction in the nurse-led pediatric allergy clinic. Allergy 2012;67:512.

231 Mashlan W, Heffey S, Jones L. Advanced nurse practitioners can lead comprehensive geriatric assessment in acute hospitals. Nurs Older People 2019:e1182.

232 McCoy C, Lane J, Kamath S, et al. Development of an occupational therapy advanced practitioner role within a multidisciplinary early inflammatory arthritis clinic in Salford. Rheumatology 2019;58.

233 McCrudden MS, Gill D, Fleming G, et al. The impact of a pharmacist independent prescriber on the discharge processes at the weekend in an acute Hospital. Int $J$ Integr Care 2017;17:A548

$234 \mathrm{McCulloch} \mathrm{K}$. The quality of the service provided by retrieval nurse practitioners is comparable to that of medical staff: perceptions of medical and nursing staff from referring hospitals. Pediatr Crit Care Med 2011;12:A118.

235 McNeilly NE, Waterfield J. A service evaluation of a physiotherapy extended scope practitioner community-led injection service. Rheumatology 2012;51:iii59.

236 Moore K, Harrand R, Hicks J, et al. Can a consultant radiographer prescribe palliative radiotherapy safely and improve service? Lung Cancer 2017;103:S59-60.

237 Mullen L, Jones C. A service evaluation of a new nurse consultantled basal cell carcinoma clinic. Dermatol Nurs 2014;13:39-44 https://www.ingentaconnect.com/content/bdng/dn/2014/00000013/ $00000003 / a r t 00005$

238 Pritchard A, Taylor A, Foran B, et al. Evaluating the impact of the head \& neck specialist radiographer on patient experience in radiotherapy. Radiography 2020;26:S23.

239 Punt L. Patient-centred quality care: radiographer-led brachytherapy and novel service redesign. Imag Oncol Soc Radiograph 2010:54-9 https://www.sor.org/system/files/article/ 201110/imaonc10webres.pdf\#page $=54$

240 Rabey M, Morgans S, Barrett C. Orthopaedic physiotherapy practitioners: surgical and radiological referral rates. Clin Govern Int J 2009;14:15-19.

241 Rose R-L, Probert S. Development and implementation of a hand therapy extended scope practitioner clinic to support the 18-week waiting list initiative. Hand Therapy 2009;14:95-104.

242 Ryan S, Hassell A, Thwaites C, et al. Exploring the perceived role and impact of the nurse consultant. Musculoskeletal Care 2006;4:167-73.

243 Salt E, van der Windt DA, Chesterton L, et al. Physiotherapist-led suprascapular nerve blocks for persistent shoulder pain: evaluation of a new service in the UK. Musculoskeletal Care 2018;16:214-21.

244 Slevin J, Barwell G, Youde J. Developing the role of advanced clinical practitioners in the acute care of older people. Age Ageing 2013;42:ii5-16.

245 Smith S, Comins C. Radiographer-led breast boost localisation - a service evaluation study. Radiography 2015;21:136-40.

246 Snaith B, Clarke R, Coates A, et al. How do consultant radiographers contribute to imaging service delivery and leadership? Br J Healthc Manage 2019;25:41-7.

247 Snaith B, Milner RC, Harris MA. Beyond image interpretation: capturing the impact of radiographer advanced practice through activity diaries. Radiography 2016;22:e233-8.

248 Taylor J, Gibson B, Taylor W. Developing a paediatric advanced nurse practitioner led telephone clinic for children with acute lymphoblastic leukaemia. Pediatr Blood Cancer 2018;65:S632-3.

249 Thompson C, Ramsden W. Paediatric feeding videofluoroscopy, an extended role for radiographers. Pediatr Radiol 2014;44:S368.

250 Tsang YM, Shoffren O, Kudhail J. PO-1096: the impact of advanced practice in a large radiotherapy department. Radiother Oncol 2018;127:S617. 
251 Turk A, Johansen A. Pharmacist independent prescribing - An evaluation of care for patients admitted with fragility fractures. Osteoporosis Int 2010;21:S481.

252 Williams SD, Bowron A, Morris J. Evaluation of a pharmacist independent prescriber in a hospital type 2 diabetes clinic. Diabet Med 2010;27:166.

253 Woods L. Evaluating the clinical effectiveness of neonatal nurse practitioners: an exploratory study. J Clin Nurs 2006;15:35-44

254 Woznitza N, Piper K, Burke S, et al. Chest X-ray interpretation by radiographers is not inferior to radiologists: a multireader, multicase comparison using JAFROC (jack-knife alternative Freeresponse receiver operating characteristics) analysis. Acad Radiol 2018;25:1556-63

255 Woznitza N, Piper K, Burke S, et al. Agreement between expert thoracic radiologists and the chest radiograph reports provided by consultant radiologists and reporting radiographers in clinical practice: review of a single clinical site. Radiography 2018;24:234-9.

256 Woznitza N, Piper K, Burke S, et al. Adult chest radiograph reporting by radiographers: preliminary data from an in-house audit programme. Radiography 2014;20:223-9.

257 Woznitza N, Piper K, Rowe S, et al. Immediate reporting of chest $\mathrm{x}$-rays referred from general practice by reporting radiographers: a single centre feasibility study. Clin Radiol 2018;73:507.e1-8.

258 Allan P, Dekka C, Brown R. Impact of an advanced physiotherapy practitioner-led pilot community spinal MSK service. Physiotherapy 2017;103:e121.

259 Barratt J. A case study of styles of patient self-presentation in the nurse practitioner primary health care consultation. Prim Health Care Res Dev 2005;6:329-40.

260 Barrett R, Mackenzie G. Can an advanced practitioner physiotherapist and GP from a community service work collaboratively to discharge patients from an emergency department? Physiotherapy 2017;103:e144-5.

261 Bond C, Lane K, Poland F. GP views on the potential role for pharmacist independent prescribers within care homes: Care homes independent pharmacist prescribing study (CHIPPS): 'There has to be something in it for me'. Int J Pharm Pract 2016;24:14.

262 Bond C, Maskrey V, Alldred D. Care homes independent pharmacist prescribing study (CHIPPS): experiences from a non-randomised feasibility study. Int J Pharm Pract 2017;25:5-6.

263 Bond CM, Bruhn H, Blyth A. Pharmacist-Led management of chronic pain in primary care: the experiences of patients, pharmacists and GPs. Int J Pharm Pract 2011;19:24-5.

264 Boyd MJ, Mann C, Anderson C. Evaluation of the NHS England phase 1 pilot: clinical pharmacists in general practice. Int J Pharm Pract 2019;27:4-5.

265 Bradley F, Seston E, Mannall C, et al. Evolution of the general practice pharmacist's role in England: a longitudinal study. $\mathrm{Br} J$ Gen Pract 2018;68:e727-34.

266 Caine R, Wynne C. Advanced practitioner physiotherapists in primary care: a new era. Physiotherapy 2016;102:e142.

267 Downie F, McRitchie C, Monteith W, et al. Physiotherapist as an alternative to a GP for musculoskeletal conditions: a 2-year service evaluation of UK primary care data. Br J Gen Pract 2019;69:e314-20.

268 Edwards M, Bobb C, Robinson SI. Nurse practitioner management of acute in-hours home visit or assessment requests: a pilot study. Br J Gen Pract 2009;59:7-11.

269 Furness J, Jose W, Phillips-German L. Advanced paediatric nurse practitioner (APNP) in primary care $(\mathrm{PC})$ reduced referral proportion by up to $40 \%$. Arch Dis Child 2019;104:A52.

270 Haidar E. Evaluating patient satisfaction with nurse practitioners. Nurs Times 2008;104:32-3 https://www.nursingtimes.net/roles/ nurse-managers/evaluating-patient-satisfaction-with-nursepractitioners-01-07-2008/

271 Hill D, Marr E, Smith C. Development of pharmacist independent prescribing clinics to treat opioid analgesic dependence in NHS Lanarkshire. Pharmacy 2019;7:119-32.

272 Ingram S, Pickup S, Acton T, et al. A two year service evaluation of first contact musculoskeletal (MSK) physiotherapy roles within primary care in Taunton. Physiotherapy 2019;105:e65.
273 Leask CF, Tennant H. Evaluation of an unscheduled care model delivered by advanced nurse practitioners in a primary-care setting. $J$ Res Nurs 2019;24:696-709.

274 Mannall C, Bradley F, Seston E. Role activities and perceived impact of clinical pharmacists in general practice: A survey of 'pharmacists' views. Int J Pharm Pract 2019;27:10-11.

275 Morley H, Ker K. Patient satisfaction and outcomes of MSK pain patients accessing advanced physiotherapy practitioner in primary care; a service evaluation. Physiotherapy 2019;105:e164-5.

276 Neylon J. Nurse-led management of chronic disease in a residential care setting. Nurs Older People 2015;27:22-6.

277 Quicke JG, Cottrell E, Duffy H, et al. Implementing and evaluating a pilot physiotherapist-led osteoarthritis clinic in general practice. Physiotherapy 2019;105:e33-4.

278 Ryan S, Dawes P, Packham J. Reducing GP attendance in patients with fibromyalgia. Rheumatology 2008;47:ii26-8.

279 Salmon P, Humphreys K, Price J, et al. Can physiotherapy first contact practitioners reduce the burden on general practitioners and improve the management of musculoskeletal conditions? Physiotherapy 2017;103:e143.

280 Seale C, Anderson E, Kinnersley P. Comparison of GP and nurse practitioner consultations: an observational study. Br J Gen Pract 2005;55:938-43.

281 Seale C, Anderson E, Kinnersley P. Treatment advice in primary care: a comparative study of nurse practitioners and general practitioners. J Adv Nurs 2006;54:534-41.

282 Sephton R, Hough E, Roberts SA, et al. Evaluation of a primary care musculoskeletal clinical assessment service: a preliminary study. Physiotherapy 2010;96:296-302.

283 Snell R, Langran T, Donyai P. Patient views about polypharmacy medication review clinics run by clinical pharmacists in GP practices. Int J Clin Pharm 2017;39:1162-5.

284 Williams A, Jones M. Patients' assessments of consulting a nurse practitioner: the time factor. J Adv Nurs 2006:53:188-95

285 Aiello M, Terry D, Selopal N. Examining the emerging roles for pharmacists as part of the urgent, acute and emergency care workforce. Clinical Pharmacist 2017;9.

286 Blakeley C, Hogg P, Heywood J. Effectiveness of UK radiographer image reading. Radiol Technol 2008;79:221-6 http://www. radiologictechnology.org/cgi/content/full/79/3/221

287 Feetham JE, Christian W, Benger JR, et al. Paediatric ED reattendance rates: comparing nurse practitioners and other clinicians. Emerg Med J 2015;32:379-82.

288 Greenwood D, Tully MP, Martin S, et al. The description and definition of emergency department pharmacist practitioners in the United Kingdom (the ENDPAPER study). Int J Clin Pharm 2019;41:434-44.

289 Hayward N. Introduction of the physiotherapy led clinic in the emergency department for suspected scaphoid fractures. Physiotherapy 2019:105:e113.

290 McClellan CM, Greenwood R, Benger JR. Effect of an extended scope physiotherapy service on patient satisfaction and the outcome of soft tissue injuries in an adult emergency department. Emerg Med J 2006;23:384-7.

291 Rouse J, George J, Rutherford K. Intubation attempts by advanced paramedic practitioners within the UK ambulance trust: a review of 805 patients. Br J Anaesth 2018;121:e8.

292 Booth L, Henwood S, Miller P. Reflections on the role of consultant radiographers in the UK: what is a consultant radiographer? Radiography 2016;22:38-43.

293 Coster S, Redfern S, Wilson-Barnett J, et al. Impact of the role of nurse, midwife and health visitor consultant. J Adv Nurs 2006;55:352-63.

294 Gerrard D. Pharmacist independent prescriber working in a community learning disability team-releasing psychiatry time and delivering STOMP. J Psychopharm 2018;32:4.

295 Hill DR, Conroy S, Brown RC, et al. Stakeholder views on pharmacist prescribing in addiction services in NHS Lanarkshire. J Subst Use 2014;19:56-67.

296 O'Brien C. Developing a pharmacist prescribing role within child and adolescent mental health services (CAMHS). Arch Dis Child 2019;104:e2. 